\title{
Transferência intratubárica videolaparoscópica de embriões ovinos fertilizados in vitro
}

Tese apresentada ao Programa de Pós-Graduação em Clínica Cirurgia Veterinária da Faculdade de Medicina Veterinária e Zootecnia da Universidade de São Paulo para obtenção do título de Doutor em Medicina Veterinária

Departamento:

Cirurgia

Área de concentração:

Clínica Cirúrgica Veterinária

Orientador:

Prof. Dr. Luis Cláudio Lopes Correia da Silva 
Autorizo a reprodução parcial ou total desta obra, para fins acadêmicos, desde que citada a fonte.

DADOS INTERNACIONAIS DE CATALOGAÇÃO-NA-PUBLICAÇÃO

(Biblioteca Virginie Buff D’Ápice da Faculdade de Medicina Veterinária e Zootecnia da Universidade de São Paulo)

Transferência intratubárica vídeolaparoscópica de embriões ovinos fertilizados in vitro / Alexandre de Faria Tabet. - São Paulo: A. F. Tabet, 2007.

73 f. : il.

Tese (doutorado) - Universidade de São Paulo. Faculdade de Medicina Veterinária e Zootecnia. Departamento de Cirúrgia, 2007.

Programa de Pós-Graduação: Clínica Cirúrgica Veterinária.

Área de concentração: Clínica Cirúrgica Veterinária.

Orientador: Prof. Dr. Luis Cláudio Lopes Correia da Silva.

1. Laparoscopia. 2. Ovinos. 3. Embrião. 4. Oviduto. 5. In vitro. I. Título. 


\section{FOLHA DE AVALIAÇÃO}

Nome: TABET, Alexandre de Faria

Título: Transferência intratubárica videolaparoscópica de embriões ovinos fertilizados in vitro

Tese apresentada ao Programa de Pós-Graduação em Clínica Cirurgia Veterinária da Faculdade de Medicina Veterinária e Zootecnia da Universidade de São Paulo para obtenção do título de Doutor em Medicina Veterinária

Data:

1

\section{Banca Examinadora}

Prof. Dr. Instituição:

Assinatura: Jugamento:

Prof. Dr. Instituição:

Assinatura: Jugamento:

Prof. Dr. Instituição:

Assinatura: Jugamento:

Prof. Dr. Instituição:

Assinatura: Jugamento:

Prof. Dr. Instituição:

Assinatura: Jugamento: 


\section{Gênesis}

Origem do mundo

No princípio criou Deus o céu e a terra.

Disse também Deus: Produzam as águas, animais viventes, que nadem nas águas; e aves, que voem sobre a terra, e debaixo do firmamento do céu.

E Ele os abençoou, e lhes disse: Crescei e multiplicai-vos, e enchei as águas do mar; e as aves do céu se multipliquem sobre a terra.

Disse também Deus: Produza a terra animais viventes, cada um segundo a sua espécie: animais domésticos, répteis e animais selvagens, segundo as suas espécies. E assim se fez.

Disse também Deus: Façamos o homem a nossa imagem e semelhança, o qual presida aos peixes do mar, as aves do céu, às bestas, e a todos os répteis, que se movem sobre a terra.

E criou Deus o homem a sua imagem...

Deus os abençoou, e lhes disse: Crescei e multiplicai-vos, e enchei a terra, e tende-a sujeita a vós, e dominai sobre os peixes do mar, sobre as aves do céu, e sobre todos os animais que se movem sobre a terra.

E assim se fez.

E viu Deus todas as coisas que tinha feito, e eram muito boas...

Assim pois foram acabados o céu, e a terra com todos os seus ornatos.

E acabou Deus no dia sétimo a obra que tinha feito... 
Devem-se buscar amigos como se buscam livros.

Acertar na procura não reside em que sejam muitos nem extraordinários, mas que sejam poucos, bons e bem conhecidos.

Mateo Alemán 


\section{DEDICATÓRIA}

Aos meus pais, a quem devo tudo. 
Qnaréa,

OKen recente amor

Tive muito prazer na realizaçãa desta $\mathscr{J}_{\text {ese, }}$

Porém, a maiar foi, que através desta...

Eu tive a sorke a prazer

De te conhecer 


\section{AGRADECIMENTOS}

Fico grato

Ao meu orientador Prof. Dr. Luís Cláudio, por ter me proporcionado a busca do conhecimento e fornecido toda condição para realização desta Tese.

À Hernan Baldassarre pelo pioneirismo na técnica de LOPU abrindo horizontes e incentivando novas pesquisas nesse campo;

À equipe pelo entrosamento, da/o

Minha auxiliar câmera, Medica Veterinária, Janaína Silva Chacon, pela determinação, humildade e dedicação no aprendizado da técnica, sem a qual seria impossível a obtenção dos resultados.

Atenciosa e sistemática Daniela Aparecida Fróes, Técnica em Enfermagem, pela agilidade e dinamismo que conferiu aos procedimentos.

Meu cabanheiro Gumercindo Donizetti Gonsalves pelo esforço na busca da perfeição às regras, pelo companheirismo e carinho na rotina dos animais.

Selecionador Edílson Ferrera Marques pelo desempenho, superação e vibração na expectativa.

À colaboração (de/a)

José Henrique Pontes, Médico Veterinário, Dir. de Produção da IN VITRO BRASIL Ltda, pela sabedoria e sensatez na colaboração deste trabalho e determinação na busca de soluções.

Equipe do Laboratório, sob a responsabilidade da Dra. Andréa Basso, que não só participou, juntamente com a Dra. Cristina Ramirez e Alexandra Castilho Ereno como trabalharam e compartilharam de coração, no desenvolvimento do projeto.

Pós-graduanda Elisa Rossi Komninou, orientada do Prof. Dr. Eduardo Birgel e à Médica Veterinária Daniela Birgel, pela demonstração de competência, segurança e precisão nos diagnósticos ultrassonográficos, além da delicadeza e respeito para com os animais. 
Prof. Dra Aline Ambrósio Magalhães, pela facilidade, paciencia e simplicidade com que transmite seu grande conhecimento, decisivo para conclusao desta Tese e um privilegio de têla conosco.

Ao apoio...

Incondicional da CABANHA TERRAUNA e participação ativa de seus proprietários Walda e Luciano Cavinato.

Dos meus pais Horácio e Sonia Tabet pelo oferecimento da propriedade e o aceite das transformações nela ocorrida.

Do Departamento de cirurgia da FMVZ - USP, na pessoa do Prof. Dr. Paulo Sergio Morais Barros na chefia da pós-graduação, sempre aparecendo nas horas certas; foi bom poder contar com o senhor.

Do Serviço de Anestesiologia da FMVZ - USP sob a coordenação da Prof. Dra Denise Tabacchi Fantoni, chefe do Serviço de Anestesiologia da FMVZ-USP, em especial Prof. Dra Aline Ambrósio Magalhães, doutorando Alex Santana, e Médica Veterinária Maria Tereza Souto; vocês realmente agarraram a idéia mesmo antes do início.

Da Tecnopec pela confiança e incentivo à pesquisa, na pessoa; M.V.Marina Berretine Paes de Barros sob a supervisão da M.V. Isabel Garcia

Da Caroatá Genética na pessoa do Dr Gustavo Ferrer, pelo mais do que aprovado sêmen fornecido (Caiçara 027).

Da Caps, Coordenação de Aperfeiçoamento de Ensino Superior pelo auxilio indispensável prestado.

À participação...

Decisiva na colaboração da Dra. Marcela Pecora Milazzotto do Departamento de Reprodução Animal da FMVZ-USP, pela dedicação e atenção dispensada na ajuda ao entendimento e elucidação na qualificação do projeto. 
Do Dr. Marcílio Michi também do VRA, pelo conhecimento e simplicidade que demonstrou na sua colaboração, em assunto tão complexo para mim que é a estatística.

Da Prof. Dra Lílian Gregori, da Clínica de Ruminantes, pela forma solícita e motivadora na transmissão de seus conhecimentos; conte sempre comigo.

Das professoras do VRA Dra Camila Vanucchi, Dra Maira Elena Assumpção e pósgraduanda Jackeline pela ajuda prestada.

Da pós-graduanda Mariana Chaparro Borja pela disposição e auxílio no piloto realizado, sempre com paciência e doçura; conserve-se sempre assim.

Da Prof ${ }^{a}$ Annelise Traldi, pela confiança em mim depositada, no treinamento das primeiras ovelhas puncionadas e exemplo de organização e disciplina.

De Marcelo Macedo, hoje da empresa ENDOVET, pela sua presença marcante no fornecimento de equipamento e instrumental, nas primeiras transferências bem sucedida que se teve notícia, com uso de sêmen Santa Inês através da FIV em Serra Negra e você estava lá.

De Camila, Cássia e Edinei pela extrema boa vontade na participação.

Dos prestativos funcionários do HOVET, Henrique Fragoso, Nice e Maria, pelo carinho e consideração no preparo dos materiais, eu os preso muito.

De Helena, Fatima, Solange, Elza e Cláudia, por eu nunca dizer: Vou ter que ir à biblioteca; e sim; Vou à biblioteca. Isto pelo carinho e dedicação que nos é transmitido logo que entramos no recinto.

Da frase questionada pelo Prof. Dr. Ângelo João Sopiglia em Livre Docência no ano de 2004. "Como desenvolver habilidade cirúrgica laparoscópica na rotina de Grandes Animais?"... Isso nunca me saiu da cabeça.

À Convivência com

Os residentes, secretários e funcionários, pela relação amistosa no cotidiano.

Os professores amigos; é deles que adquirimos experiência. 
Os alunos; é com eles que aprendemos a como passar o pouco que sabemos.

Meu amigo Dênio, por poder contar sempre com ele.

Minha mãe e meus irmãos, por estarem sempre ao meu lado.

Meu pai, em bons momentos, e por sempre agüentar o tranco nas horas mais difíceis.

Deus, por estar sempre presente. 


\section{RESUMO}

TABET, A. F. Transferência intratubárica videolaparoscópica de embriões ovinos fertilizados in vitro. [Embryo transfer in oviduc of ovine in vitro fertilized by laparoscopy]. 2007. 73 f. Tese (Doutorado em Medicina Veterinária) - Faculdade de Medicina Veterinária e Zootecnia, Universidade de São Paulo, São Paulo, 2007.

O desenvolvimento da técnica de transferência embrionária no oviduto mediante videolaparoscopia e a avaliação de produtividade da punção folicular laparoscópica (LOPU) associada à transferência embrionária laparoscópica e/ou por laparotomia videoassistida, ambas no oviduto, foram os objetivos do presente trabalho. Foram utilizados 53 animais, sendo as punções foliculares para obtenção dos oócitos realizadas em 9 ovelhas adultas estimuladas hormonalmente, chamadas doadoras. Os oócitos foram obtidos através de LOPU repetidamente com intervalo mínimo de um mês entre os procedimentos nas mesmas doadoras. Os oócitos puncionados foram maturados, fertilizados e mantidos em cultivo por até três. Os embriões clivados foram transferidos no segundo dia após a fertilização in vitro (FIV) em ovelhas receptoras com cio sincronizado. A transferência dos embriões (TE) foi realizada primeiramente em 10 receptoras por laparoscopia e em 34 receptoras por laparotomia videoassistida, sendo esta última dividida em duas etapas cronológicas. Para a realização da TE por videolaparoscopia, foi introduzido, inicialmente, um trocarte de $5 \mathrm{~mm}$ na linha média ventral próximo à glândula mamária para passagem da óptica. Um segundo portal, crânio-lateral ao primeiro, foi criado para introdução de pinça de manipulação de ovário. Confirmada a existência de corpo lúteo (CL) em um dos ovários, um trocarte foi inserido no lado oposto a esse para passagem de cateter de Foley. Sua função foi auxiliar na exposição e abertura da fímbria. Um cateter urinário, contendo os embriões foi então introduzido na porção inicial do oviduto para deposição dos mesmos. Obteve-se 8 fetos 
resultantes da transferência por laparoscopia (10 receptoras), 10 fetos resultantes da primeira etapa da transferência por laparotomia (14 receptoras) e 30 fetos resultantes da segunda etapa da laparotomia (20 receptoras). A média de fetos por sessão de LOPU foi de 1 para transferência laparoscópica, 1,3 na primeira etapa da transferência por laparotomia e 3,3 na segunda etapa de laparotomia. A transferência embrionária videolaparoscópica de embriões clivados no oviduto mostrou resultado positivo na produção de fetos, podendo ser considerada técnica promissora. Quando associada à LOPU, a transferência embrionária no oviduto por laparoscopia / laparotomia videoassistida, apresentou resultados superiores aos relatados na literatura com a transferência intra-uterina de embriões FIV.

Palavras-chave: Laparoscopia. Ovinos. Embrião. Oviduto. In vitro. 


\begin{abstract}
TABET, A. F. Embryo transfer in oviduc of ovine in vitro fertilized by laparoscopy. [Transferência intratubárica videolaparoscópica de embriões ovinos fertilizados in vitro ]. 2007. 73 f. Tese (Doutorado em Medicina Veterinária) - Faculdade de Medicina Veterinária e Zootecnia, Universidade de São Paulo, São Paulo, 2007.
\end{abstract}

The development of the technique of embryo transfer in oviduct through videoassisted laparoscopy and the demonstration of productive association between laparoscopic follicle aspiration (LOPU) and embryonic transfer laparoscopy and / or open surgery (videoassisted laparotomy)both in oviduct was the goal of the work. From the 53 animals used in the study, follicular puncture was used to obtain oocytes from 9 adult ewes for super-ovulated with hormonally stimulation, referred to as the donors. The oocytes were obtained through repeated LOPU with minimum intervals of one month from the same donor. The retrieved oocytes were matured, fertilized with frozen semen and cultured in vitro for up to two days after IVF. The cleaved embryos were transferred on the second day after IVF into synchronized receptor ewes. The transfer of embryos was first done in 10 receptors through laparoscopy and then in 34 receptors through video-assisted laparotomy, the latter being divided into two chronological stages. For the development of ET by video-assisted laparoscopy, a $5 \mathrm{~mm}$ trocar was initially introduced ventral midline near the mammary gland for passage of the laparoscope. A second portal, in a craniolateral position was used for passage of another $5 \mathrm{~mm}$ trocar for introduction of forceps to manipulate the ovary. After confirming the existence of CL in one of the ovaries, a trocar was inserted on the opposite side for passage of the Foley catheter, to assist in the exposure and opening of the fimbria. A urinary catheter, containing the embryo, was then introduced into the initial portion of the oviduct for deposition of the embryos. There were 8 fetuses resulting from the transfer by 
laparoscopy (10 receptors), 10 fetuses resulting from the first stage of the transfer by laparotomy (14 receptors) and 30 fetuses resulting from the second stage of the laparotomy (20 receptors). The average number of fetuses per session of LOPU was 1 for laparoscopic transfer, 1.3 for the first stage of the transfer by laparotomy and 3.3 in the second stage of laparotomy. The technique of embryo transfer through video-assisted laparoscopy with cleaved embryos in oviduct was thus shown to a positive fetus's result of production, and will be promising. When associated with LOPU, the transfer of embryos in oviduct by laparoscopy / video-assisted laparotomy presented better results then other authors when compare intrauterine IVF embryo transfer.

Keywords: Laparoscopy. Sheep. Embryo. Oviduct. In vitro. 


\section{SUMÁRIO}

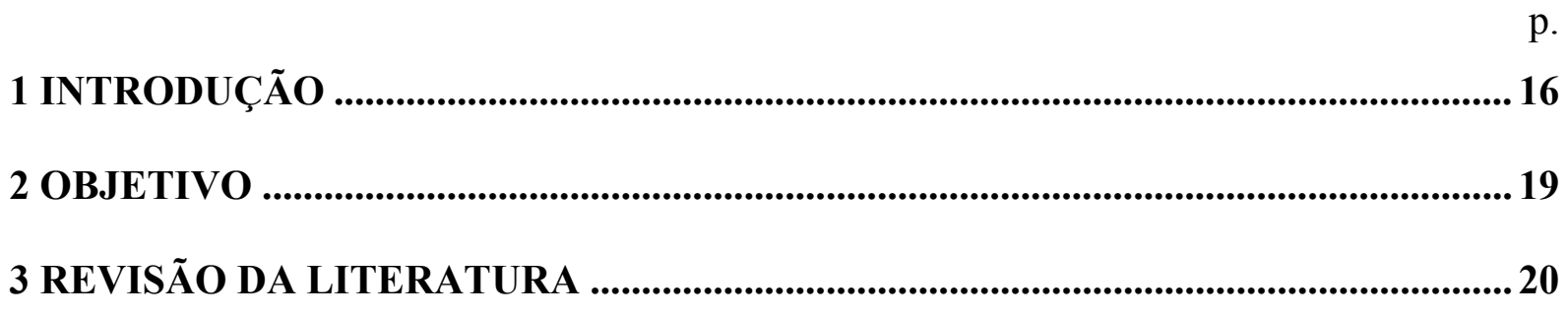

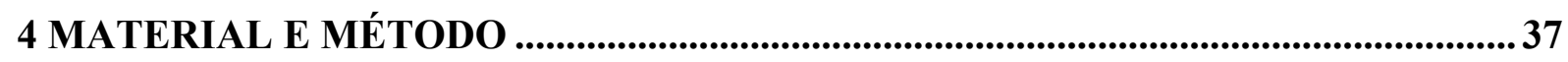

5 RESULTADOS

6 DISCUSSÃO ...............................................................................................................................56

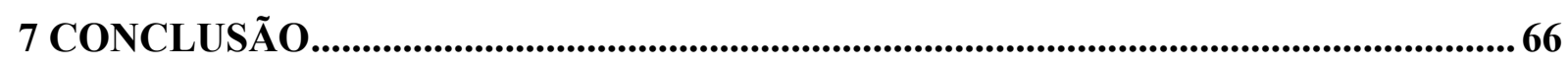

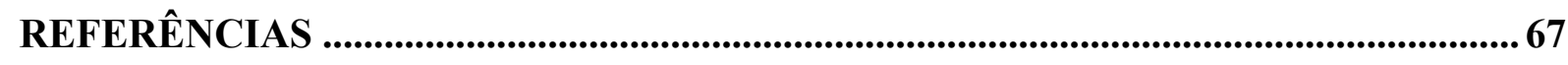

ANEXO 


\section{INTRODUÇÃO}

A transferência de embriões (TE) é método de reprodução artificial baseado na retirada, antes da implantação uterina, de embriões gerados por uma fêmea doadora de grande potencial genético e transferidos em fêmeas receptoras, chamadas barrigas de aluguel. Estas, por sua vez, desenvolvem o embrião7(Figuras 1 e 2) até o nascimento.

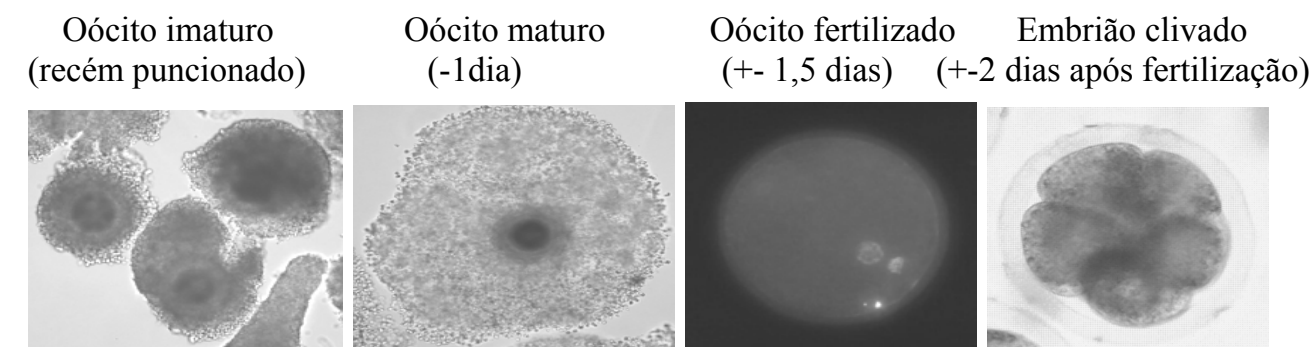

Figura 1. Estádios de desenvolvimento ovariano e intratubário de oócitos e embrião (in vivo)

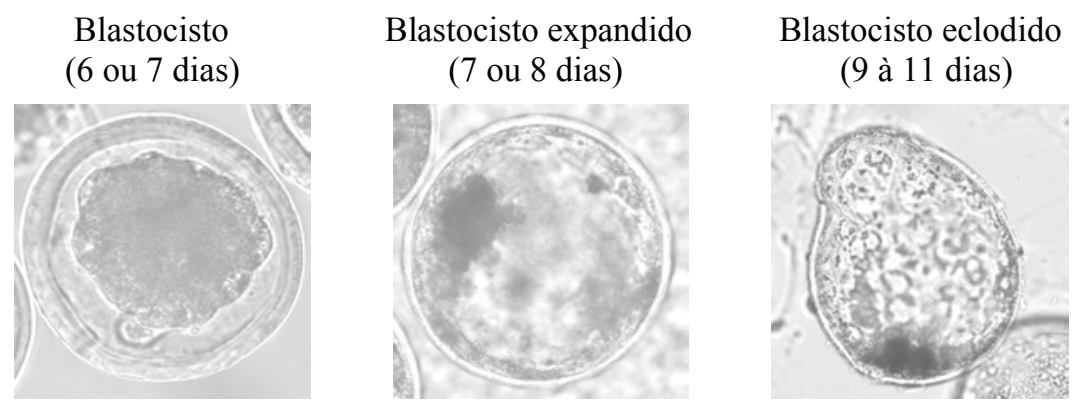

Figura 2. Estádios de desenvolvimento embrionário intra-uterino (in vivo)

O principal intuito da TE é aumentar o número de descendentes das fêmeas de alto valor genético e/ou impossibilitadas de gestação ou criação de sua prole.

\footnotetext{
1,2 Imagens de desenvolvimento embrionário bovino, cedidas pelo Laboratório de FIV, Clonagem e Transgenia Animal - FMVZ - USP
} 
A TE em ovinos, no Brasil e no mundo, é feita comercialmente com melhores resultados por monta natural, inseminação artificial (IA) cervical superficial com sêmen a fresco ou IA laparoscópica com sêmen a fresco ou congelado.

Para a utilização de sêmen congelado são necessárias uma ou até duas doses inseminantes, em diferentes momentos, tendo em vista a dificuldade em se estabelecer protocolos precisos de superovulação ou o momento ideal da inseminação. Estas dificuldades são motivos de pesquisas recentes que relacionam estação do ano, idade, raça, clima, estresse, protocolos hormonais e melhor local para deposição do sêmen.

A colheita dos embriões feita no sexto ou sétimo dia após a inseminação ou cobertura tem, indiscutivelmente, seus melhores resultados através da laparotomia com exteriorização dos cornos uterinos e lavagem interna do útero para a recuperação dos embriões. Como limitação da técnica, podem ocorrer aderências a partir da primeira intervenção cirúrgica, gerando o comprometimento da manipulação após o segundo procedimento.

As dificuldades e limitações da colheita de embriões acima citadas, ressaltadas em outros estudos (COGNIE et al., 2003; 2004, COX, 2005; TIBARI et al., 2005), motivaram alguns pesquisadores a estudar a produção in vitro (PIV) de embriões ovinos.

Apresentada como possível alternativa para animais de alto valor genético, acometidos por temporária ou irreversível infertilidade, Baldassarre et al. (1996), através de punção folicular laparoscópica (LOPU), demonstraram a viabilidade da técnica de PIV de embriões ovinos.

Através da exposição dos ovários por laparotomia para punção folicular (OPU), Ptak et al. (1999) obtiveram 14 fetos em 17 transferências. Em 2002, Papadopoulos et al. utilizaram ovários de abatedouro, obtendo 23 fetos de 35 transferências.

Martínez et al. (2006) realizaram LOPU e obtiveram 27 fetos diagnosticados aos sessenta dias de prenhez num total de 64 receptoras transferidas. Em 2007, Cox e Alfaro, após 
rigorosa seleção dos embriões, apresentaram como resultado da LOPU 18 cordeiros nascidos de 23 receptoras transferidas. Em todos os trabalhos consultados os embriões foram transferidos no corno uterino, no sexto ou sétimo dia após a fecundação, já em estádio de blastocisto.

Uma das dificuldades do sistema de PIV de embriões ovinos é o cultivo após a primeira clivagem, tempo em que ocorrem as maiores perdas embrionárias, por mecanismos ainda não completamente elucidados.

Buscando minimizar os efeitos deletérios do cultivo in vitro neste período, o presente estudo propõe introdução do embrião clivado diretamente no oviduto da receptora, no segundo dia após a fecundação, através de laparoscopia ou laparotomia videoassistida. 


\section{OBJETIVO}

- Desenvolver a técnica de TE no oviduto mediante videolaparoscopia.

- Demonstrar a produtividade da LOPU associada à transferência embrionária no oviduto por laparoscopia ou laparotomia videoassistida. 


\section{REVISÃO DE LITERATURA}

\subsection{Laparoscopia}

Apesar de conhecida desde o início do século, a laparoscopia apresentou evolução lenta em medicina veterinária, tendo seu desenvolvimento mais acentuado entre as décadas de 70 e 80, principalmente associada aos avanços científicos na área de reprodução animal. Apenas nos últimos 15 anos tivemos maior ênfase aos aspectos cirúrgicos, ficando assim a cirurgia laparoscópica com o seu principal desenvolvimento apenas a partir do início da década de 90 com o uso da microcâmera.
Segundo Decker ${ }^{8},(1952$ apud SILVA; MEGALE, 1971, p. 91) :
“ Kelling foi o primeiro a realizar, em 1901, a celioscopia em cães vivos, empregando o telescópio de Nitze, que foi introduzido na cavidade peritoneal através da cânula de um trocarte. A fim de melhorar o campo visual, provocou artificial e previamente o pneumoperitônio".

Em 1949, McEntee realizou peritonioscopia dos órgãos reprodutivos internos de vacas, porém de forma limitada, pois o instrumento utilizado não foi completamente satisfatório, causando queimadura dos tecidos devido à intensa produção de calor pela fonte luminosa (MEGALE; FINCHER; MCENTEE, 1956).

Utilizando técnica mais aprimorada e dispondo de melhor equipamento, Megale; Fincher e McEntee (1956), realizaram a peritonioscopia em vacas com três abordagens: através do fórnix vaginal, pela fossa paralombar direita ou esquerda com uma cânula rígida fixada permanentemente, realizando repetidos exames.

\footnotetext{
${ }^{8}$ DECKER, A. A new technique in gynecologic and obstetrics diagnosis. Philadelphia: W. B. Saunders, 1952. $977 \mathrm{p}$.
} 
Os autores concluíram que, para visualização dos órgãos reprodutivos internos de bovinos, o acesso pelo fórnix vaginal é de pouco valor, já o acesso pela fossa paralombar permitiu visualização satisfatória dos ovários, ovidutos e útero na maioria dos casos, sendo o flanco direito mais indicado por diminuir o risco de punção do rúmen e propiciar maior espaço.

A partir da década de 70 , muitos estudos foram realizados com o intuito de observar principalmente a função ovariana em diferentes espécies animais.

A técnica de peritonioscopia foi descrita em égua por Silva e Megale (1971) com acesso pelo fórnix vaginal e fossas paralombar direita e esquerda. Os resultados demonstraram que o acesso paralombar permite melhor visualização dos órgãos genitais, sendo indicada a fossa esquerda para baço e os órgãos genitais localizados à esquerda da cavidade abdominal, e a fossa direita para os órgãos genitais localizados à direita e fígado. Para a observação de alças intestinais os dois acessos foram considerados eficientes pelo autor, porém sem uma descrição detalhada de sua distribuição.

Os principais riscos na laparoscopia estão associados à punção de vísceras e vasos quando da passagem do trocarte ou da agulha de Verres. Alterações cardiopulmonares podem ocorrer em conseqüência à compressão diafragmática causada pelo pneumoperitônio (JOHNSON; TWEDT, 1977). Animais obesos, com excessivo acúmulo de gordura intraabdominal ou excessivamente grandes prejudicam a visualização dos órgãos abdominais (JONES, 1990). Com base em experimento realizado em bovinos, Schneider e Otto (1974) apontaram a insuflação de gás retroperitoneal como a principal complicação da utilização de pneumoperitônio.

Phillipo et al. (1971), estudando o diagnóstico precoce de gestação em ovelhas por via laparoscópica, utilizaram o decúbito dorsal para posicionamento dos animais e a insuflação da cavidade abdominal com dióxido de carbono, o que propiciou uma melhor visualização da 
cavidade devido ao afastamento das vísceras da parede abdominal. Alguns anos mais tarde Phillippo e Rhind (1977) publicaram trabalho semelhante ao anterior, porém realizando o procedimento com o animal em estação e via de acesso pelo flanco direito, evitando desta forma o jejum prolongado e diminuindo riscos anestésicos.

Wishart e Snowball (1973) utilizaram pneumoperitônio de dióxido de carbono com pressão intra-abdominal de 1,5 a $2 \mathrm{lb} /$ pol $^{2}$ para a realização de laparoscopia em vacas, não ocorrendo alterações cardiovasculares em conseqüência à distensão abdominal. Neste experimento a luz foi transmitida a partir de uma fonte de luz por cabo de fibra óptica à semelhança dos equipamentos atuais.

Com a finalidade de estudar os órgãos reprodutivos internos da égua por via laparoscópica, Wilson (1983) empregou o acesso pelo flanco esquerdo. Para distender o abdômen utilizou insuflador automático de óxido nitroso. A pressão intra-abdominal foi mantida constante não excedendo $20 \mathrm{mmHg}$. O autor sugeriu o método para monitorar problemas de infertilidade, para biópsia ovariana, biópsias de massas pélvicas, coleta de material para cultura bacteriana de infundíbulo, exame de patência tubária e aspiração de cistos ovarianos. No estudo realizado, os animais foram sedados com xilazina, seguido de administração intravenosa de morfina e anestesia local com lidocaína.

\subsection{Laparoscopia em Ovinos (Inseminação Artificial)}

Na produção de ovinos, a laparoscopia foi utilizada primeiramente em larga escala na Inseminação artificial (IAL). Trabalhos envolvendo grande número de animais comprovaram a viabilidade comercial da técnica. 
Desenvolvida por Killen e Caffery (1982), a técnica foi realizada através de três portais de acesso, um para óptica, lateral a linha média e cranial à bexiga, um segundo no lado oposto para passagem da probe de manipulação e um terceiro cranial na linha média, para introdução da pipeta contendo o sêmen.

Moses et al. (1997) ressaltaram os baixos índices de prenhez obtidos através da inseminação cervical (IC) com sêmen congelado. Segundo os autores tais índices são inaceitáveis para utilização em programas de melhoramento genético. Comentaram também sobre possível limitação da laparoscopia referente a custos e treinamento profissional. O método utilizado para sincronização e fatores ambientais que determinam resposta ovulatória são aspectos determinantes para o sucesso do programa.

Em programa de melhoramento genético foram utilizadas 1824 ovelhas e 480 borregas inseminadas através da laparoscopia em duas fazendas localizadas em Santa Cruz, Argentina (MOSES et al., 1997). Os mesmos autores obtiveram um índice de 63\% de prenhez em ovelhas e 55\% nas borregas com resultados considerados satisfatórios para o programa.

Em trabalho a campo com 28.447 ovelhas realizado na Austrália, Hill et al. (1998) obtiveram através de IAL um índice de prenhez constante durante os cinco anos da pesquisa, os autores verificaram diferença entre o numero de ovelhas prenhes durante os meses trabalhados (novembro a maio), diferenças entre os carneiros utilizados e quanto à época do ano em que foram coletados. Houve também uma superioridade nos índices com sêmen a fresco $(82.2 \%)$ comparado ao congelado $(71.6 \%)$.

Em 2003, Ehling et al. estudaram a produção de zigotos através da IAL avaliando sêmen em diferentes formas de conservação e duas concentrações diferentes. Obtiveram melhores resultados com sêmen a fresco em alta concentração $(64.7 \%)$ contra $49 \%$ com sêmen resfriado e $39.6 \%$ com sêmen congelado. 
Utilizando-se da IAL com sêmen congelado e inseminação cervical com sêmen fresco Anel et al. (2005) compararam os dois métodos, bem como alguns fatores relacionados aos índices de prenhez. Foram no total 44.448 procedimentos realizados. Através da IAL $45 \%$ das ovelhas pariram, contra $31 \%$ das inseminações cervicais. Houve uma diferença anual e diminuição da fertilidade em fêmeas acima de quatro anos, houve também diferenças entre as estações do ano, carneiro utilizado e as fazendas onde o programa foi instituído. Também foram observadas diferenças significativas sobre os resultados obtidos em relação aos profissionais que realizaram a técnica.

Em 2006, Anel et al. fizeram algumas considerações relativas aos índices de prenhez de IA encontrado. Comentam sobre o uso mais escasso das técnicas de inseminação artificial em ovinos quando comparada a outras espécies. Segundo os autores, isso se deve não somente aos resultados irregulares de fertilidade, como também às dificuldades com o uso de sêmen congelado.

Entre outros fatores, as dificuldades citadas acima foram atribuídas à necessidade de treinamento dos profissionais em laparoscopia, bem como condições mínimas de estrutura para realização da técnica a campo.

Os mesmos autores foram categóricos quanto à divisão dos programas comerciais de IA em ovinos em duas categorias: uso de sêmen a fresco com deposição intracervical superficial (IC) e, mais restrita, com sêmen congelado e deposição intrauterina através da laparoscopia.

A técnica de inseminação intracervical, cervical superficial ou simplesmente cervical, utilizada por Arndtbirkenhof ([2005?]) consistiu na utilização de espéculo vaginal, disposto de fonte luminosa (Figura 3), que após sua lubrificação e elevação do trem posterior do animal (Figura 4), um aplicador contendo o sêmen foi então inserido após o primeiro anel da cérvix (Figura 5 e 6). 


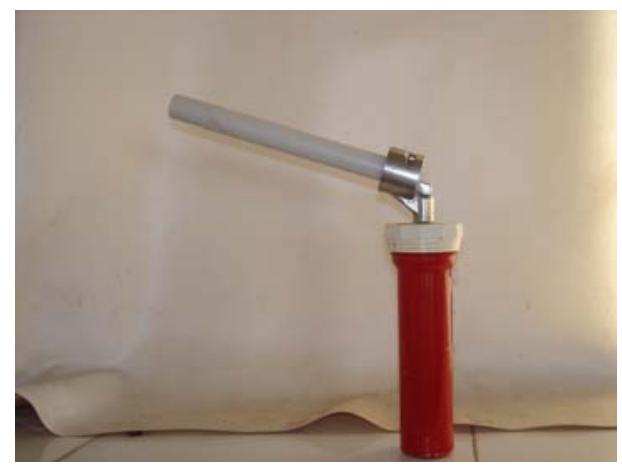

Figura 3 - Espéculo vaginal disposto de fonte na luminosa utilizado na IC

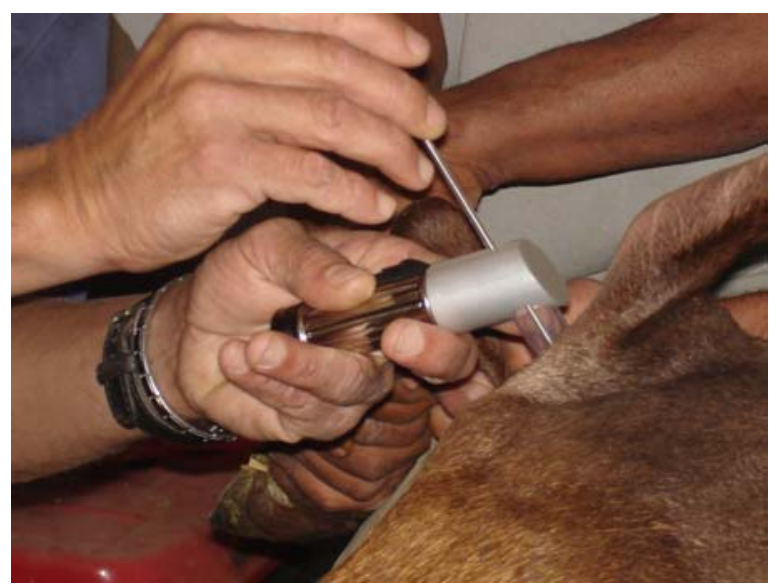

Figura 5 - Imagem digitalizada demonstrando a introdução do aplicador para IC

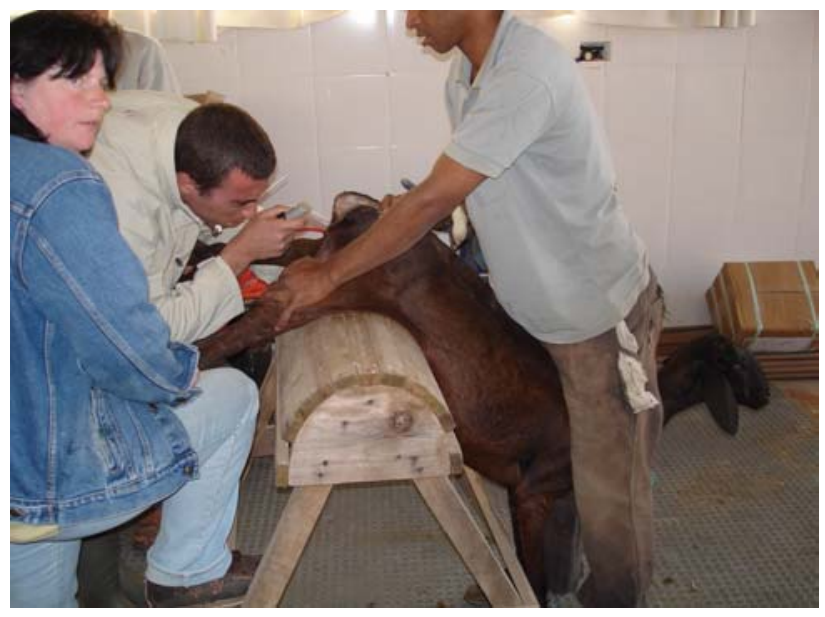

Figura 4 - Imagem digitalizada demonstrando o posicionamento do animal e introdução do especulo para IC

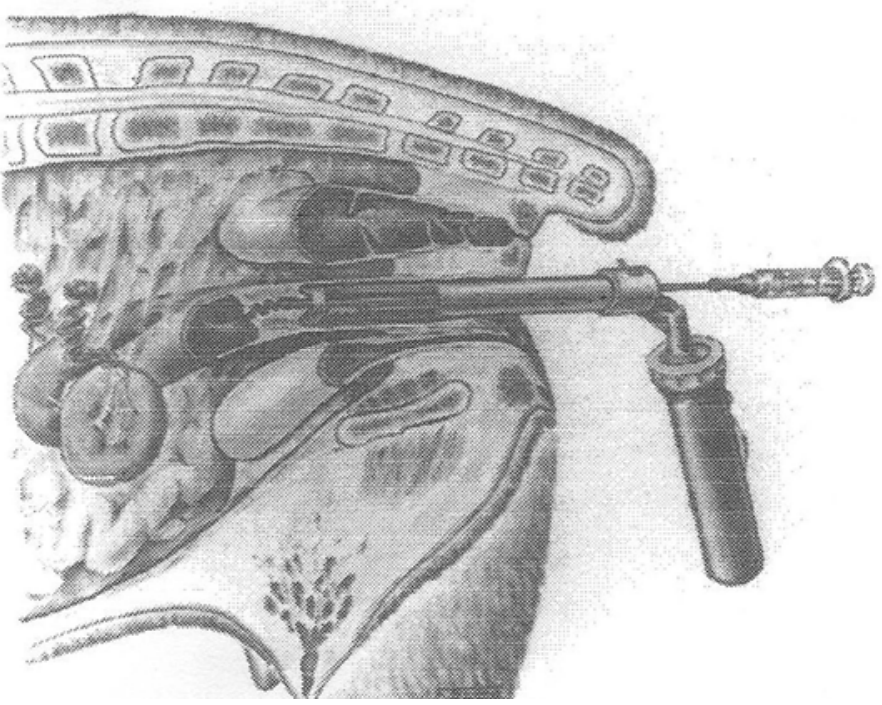

Figura 6 - Imagen digitalizada de desenho esquemático representando espéculo introduzido no vestíbulo vaginal com introdução do aplicador no início da cérvix

Segundo os autores ${ }^{9}$ (ANEL et al., 2006) a IAL é o único método de introdução de sêmen no útero de ovelhas sem redução nos índices de fertilidade. Os índices conseguidos 
com IA transcervical (IATC) são ainda bastante reduzidos. Segundo Raynal e Houdeau ${ }^{10}$ (2004 apud ANEL, 2006, p. 36), a IATC induz pequenos danos em zona sensível do cérvix, prejudicando a implantação embrionária e provoca desequilíbrios hormonais no período pósovulatório.

Também pensando nas limitações da IA em ovinos e visando obter maiores índices de deposição de sêmen no espaço intra-uterino, a equipe de reprodução da Embrapa Caprinos buscou avaliar um protocolo de inseminação, o qual consiste em fixar a cérvix, tracionar a mesma até a abertura vulvar e manipular a pipeta de IA através dos anéis cervicais. Foi adotada pipeta em miniatura e testados dois métodos de contenção das fêmeas, brete e maca, bem como o efeito da administração de cloridrato de bromexina na passagem da pipeta através da cérvix, substância que supostamente facilitaria sua passagem. Entre os métodos, não se observou diferença. Obteve-se um índice considerável de passagem cervical completa nas ovelhas multíparas e primíparas $(33,0 \%)$ em relação as nulíparas $(0,0 \%)$, porém, os resultados de fertilidade foram baixos $(19,66 \%)$, levando a acreditar que o maior empecilho para a I.A. pela via transcervical em ovelhas não seja a cérvix isoladamente (SALLES, [2004?]).

Grandes diferenças foram observadas entre as taxas de prenhez nos diferentes trabalhos consultados. Tais diferenças estiveram relacionadas à forma de conservação do sêmen; à propriedade aonde o programa de IA foi realizado (condições de manejo); à época do ano; à idade dos animais e número de crias; à proximidade ao parto anterior (menos de 10 semanas); ao carneiro utilizado e à diferença encontrada entre os técnicos que realizaram a laparoscopia (ANEL et al., 2005).

\footnotetext{
${ }^{10}$ RAYNAL P.; HOUDEAU, E. Comparison of the uterine reflex activity during artificial insemination and mating in the ewe. Journal de Gynecologie Obstetrique et Biologie de la Reproduction, v. 33, p. 725-733, 2004.
} 
O'meara et al. ${ }^{11}$ (2005 apud ANEL et al., 2006, p. 38) referem-se a FIV como o mais importante método de avaliação do poder de fertilização do sêmen, existindo uma estreita correlação entre fertilidade in vivo e o índice de clivagem in vitro.

\subsection{Colheita e transferência de embriões in vivo}

Através de laparotomia mediana ventral, Armstrong e Evans (1983) realizaram colheita de embriões através de laparotomia mediana ventral, seguida de exposição dos cornos uterinos (Figura 7). Na seqüência, realizou-se a introdução de um cateter de Foley no lúmen do corno uterino, próximo à sua bifurcação, no sentido do oviduto (Figura 8). Uma agulha para infusão de solução tamponada (Figura 9) foi também introduzida no corno uterino, porém mais próximo do oviduto e em seu sentido. Os embriões foram drenados juntamente com a solução, através do cateter. Da mesma forma procedeu-se no corno contra-lateral.

${ }^{11}$ O'MEARA C. M.; HANRAHAN J. P.; DONOVAN, A.; FAIR, S.; RIZOS, D.; WADE, M.; BOLAND, M. P.; EVANS A. C.; LONERGAN, P. Relationship between in vitro fertilisation of ewe oocytes and the fertility of ewes following cervical artificial insemination with frozen-thawed ram semen. Theriogenology, v. 64, p. $1797-$ $1808,2005$. 


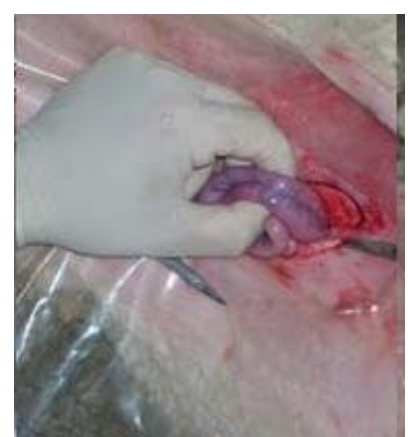

Figura 7 Exteriorização dos cornos uterinos após laparotomia mediana ventral

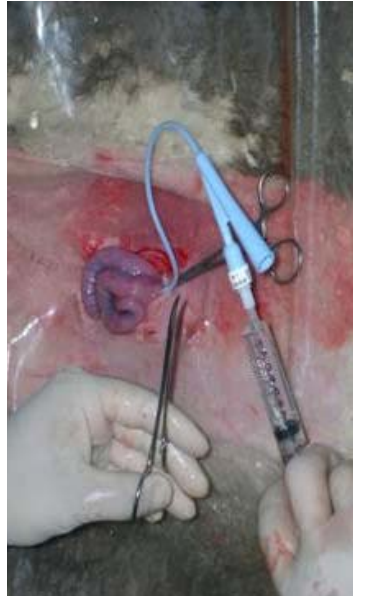

Figura 8 Imagem digitalizada demonstrando a introdução de Cateter de Foley introduzido no corno uterino

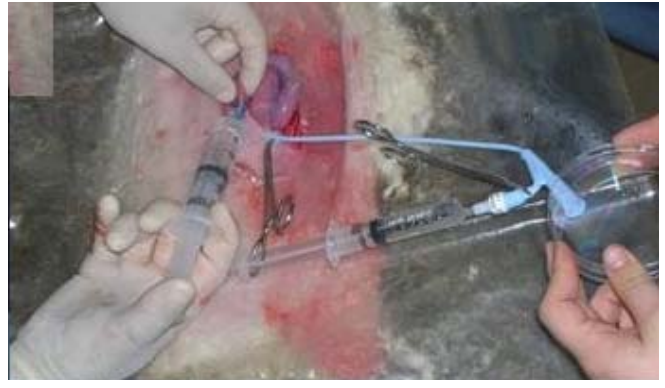

Figura 9 Imagem digitalizada demonstrando a infusão de solução para recuperação dos embriões através do cateter

A técnica de TE intra-uterina laparoscópica foi descrita primeiramente por Schiewe et al. (1984) com a utilização de dois portais de acesso. Um primeiro portal foi realizado na linha média ventral, entre a glândula mamária e cicatriz umbilical, para inserção do primeiro trocarte de $10 \mathrm{~mm}$ e introdução da óptica. Um segundo trocarte, de $6 \mathrm{~mm}$ foi inserido no quadrante caudal, ipsilateral ao corno selecionado para transferência. Este portal objetivou a introdução de pinça para apreensão do corno uterino. Na seqüência, um cateter percutâneo foi inserido no útero no sentido do oviduto, para introdução de cateter urinário contendo os embriões. Os autores comentaram sobre uma maior longevidade das receptoras com a técnica. Da mesma forma, assim o fizeram Cognié e Baril (2002), relatando mesma eficácia em taxa de prenhez $z^{12}$ (70 a 75\%) quando comparada à técnica por laparotomia com auxílio da óptica (Figura 10).

A técnica de TE por laparotomia com auxilio da óptica consiste na introdução de dois portais, em lados opostos à linha média, um para óptica e um segundo para pinça de

\footnotetext{
7,8,9 Imagens digitalizadas cedidas pela Prof Dra Lílian Gregori em estágio de Melina Marie Wasuoka na empresa Genstock, Nova Zelândia.
} 
apreensão do corno uterino. Este por sua vez foi exteriorizado, através do prolongamento da incisão de pele e divulsão da musculatura. $\mathrm{O}$ embrião foi introduzido no corno uterino ${ }^{13}$ (Figura 10), conforme descrito anteriormente.

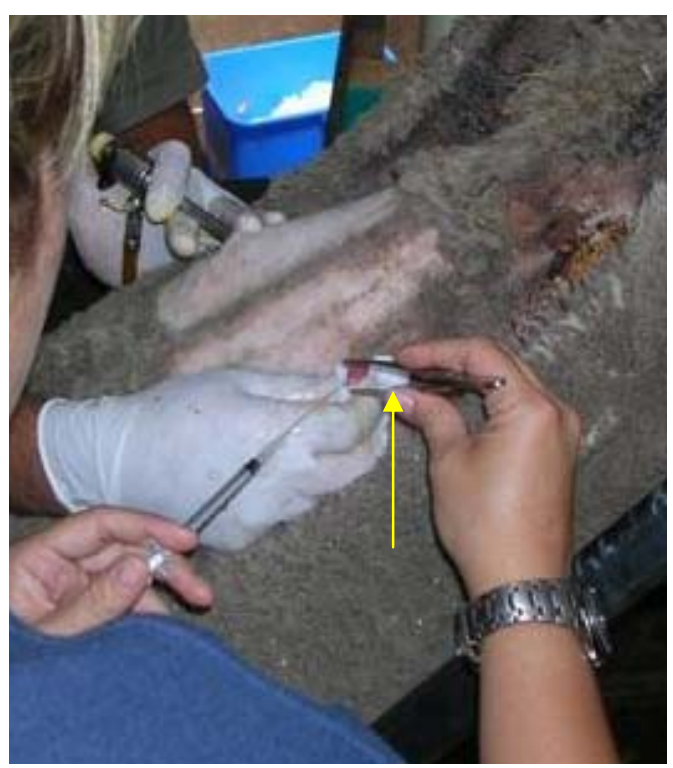

Figura 10 - Imagem digitalizada demonstrando a introdução do embrião com cateter inserido no corno uterino (seta amarela)

Durante um período de oito anos, um total de 328 ovelhas doadoras de embrião foram utilizadas por Bari et al. (2001) em programas de transferência embrionária convencional. Os autores obtiveram média de 8,6 embriões resgatados por doadora, porém, não comentaram sobre os índices de prenhez obtidos.

McEvoy et al. (1996) em pesquisa com 18 ovelhas superovuladas avaliando a IAL em dois diferentes tempos (48 e 60 horas após a retirada dos pressários vaginais com progesterona) concluíram que o retardo do desenvolvimento embrionário foi a principal consequência de falha da inseminação e não a falência na fertilização dos oócitos. Sendo assim, o tempo de inseminação não interfere na taxa de resgate embrionária e sim na

\footnotetext{
${ }^{13}$ Imagens digitalizadas cedidas pela Prof Dra Lílian Gregori em estágio de Melina Marie Wasuoka na empresa Genstock, Nova Zelândia.
} 
continuidade de seu desenvolvimento. Há uma dificuldade em se precisar o melhor momento para realização da IA em ovelhas superovuladas, portanto a quantidade de estruturas recuperadas nem sempre corresponde a um bom índice de embriões transferíveis..

Os autores obtiveram uma taxa de ovulação de 9.2 em média e 4.9 embriões recuperados por doadora

Valores semelhantes foram obtidos por Lymberopoulos et al. (2001). Do total de 6.3 embriões em média recuperados por doadora, 4.9 estavam fertilizados. Foram 229 corpos lúteos observados de um total de 20 doadoras, sendo a taxa de recuperação $57 \%$.

Avaliando diferentes protocolos hormonais de superovulação, D’Alessandro et al. (2005) obtiveram, respectivamente, nos quatro grupos de tratamento: 7,6, 8,3, 8,9 e 11,4 estruturas totais por doadora sendo que, destes, o número de embriões transferíveis por doadora foi de 7,3, 5,2, 6,2 e 6,4, respectivamente. Os autores concluíram haver diferença significativa entre os protocolos de superovulação testados. A fertilização se procedeu através da monta natural.

Bicudo et al. (2007), em aplicação do sêmen congelado em IA e TE, acreditaram ser válida a afirmação de D’Alessandro et al. (2005) em referência à falha da fertilização após a superovulação como uma das principais causas do insucesso da TE. Os autores ressaltaram ainda a necessidade de ponderar o tipo e a qualidade do sêmen utilizado, além do local de deposição dos espermatozóides para se obter o maior sucesso em programas de transferência de embriões.

Green et al. (2007a) também compararam dois diferentes protocolos hormonais de superovulação e obtiveram a média de 9.2 folículos produzidos por doadora com 5.4 embriões transferíveis por doadora em seu melhor grupo. No mesmo ano, Green et al. (2007b) em grupo controle com 48 embriões produzidos in vivo e transferidos a fresco, obtiveram taxa de prenhez de $50 \%$. 


\subsection{Produção in vitro de embriões}

Snyder; Dukelow (1974) observaram a atividade ovariana de ovelhas e determinaram os momentos de ovulação. Também através da laparoscopia fizeram diagnóstico precoce de prenhez entre 15 e 17 dias, confirmados aos 24 e 30 dias. Os autores realizaram a laparoscopia em dias alternados durante onze dias, num total de 170 procedimentos em 19 ovelhas, relatando não haver efeitos adversos com a repetição dos procedimentos. Durante a observação dos ovários, os autores puncionaram alguns folículos, com recuperação de oócitos. Foi o primeiro relato da técnica de LOPU consultado.

Mais tarde Baldassarre et al. (1994) comprovaram a utilidade da técnica, desenvolvendo pormenores ainda não estudados como o tipo de agulha, pressão de vácuo, índice de recuperação dos oócitos e qualidade dos mesmos.

Com relação às aderências ocasionadas pela laparotomia e à exposição dos cornos uterinos na técnica de colheita de embriões, a LOPU se mostra mais eficiente, visto que tais eventos são muito menos freqüente, podendo ser realizada sem seqüelas, em intervalos curtos e por inúmeras vezes, (SNYDER; DUKELOW, 1974; BALDASSARRE et al., 1996; KÜHHOLZER et al., 1997; ALBERIO et al., 2002).

A extrema variação entre as respostas individuais nos tratamentos superovulatórios na TE convencional motivaram Alberio et al. (2002) a utilizarem-se da fertilização in vitro (FIV). Segundo Cognié ${ }^{14}$ (1999 apud ALBERIO, 2002, p.81), 20\% das ovelhas não produzem embriões transferíveis na colheita. Somando-se, há formação de aderências que impossibilitam procedimentos sucessivos na mesma doadora (COGNIE et al. 2003, 2004; COX, 2005; TIBARI et al. 2005).

\footnotetext{
${ }^{14}$ COGNIE, Y. State of the art in sheep-goat embryo transfer. Theriogenology, v. 51, p. 105-116, 1999.
} 
Com embriões clivados produzidos in vivo e colocados em cultivo in vitro, Gardner et al. (1994) compararam dois meios diferentes de cultivo in vitro e obtiveram $67 \%$ de embriões desenvolvidos até o estádio de blastocisto em seu melhor grupo.

Os autores acima selecionaram os melhores embriões e transferiram em receptoras com $62 \%$ de taxa de prenhez (26 embriões em 13 receptoras) sendo $78 \%$ (16 embriões em 8 receptoras) a taxa de prenhez do grupo controle (produzido e cultivado in vivo).

Thompson et al. (1995), com embriões clivados produzidos in vivo e in vitro (ovários de abatedouro), testaram dois meios diferentes de cultivo. Os autores não observaram diferença significativa quanto à quantidade de embriões transferíveis entre os meios testados. O número de fetos diagnosticados produzidos in vitro foi de 18 em 29 receptoras. Produzidos in vivo e cultivados in vitro foram 20 fetos em 34 receptoras. Foram transferidos dois embriões por receptora.

Também com ovários provenientes de abatedouros, Brown e Radziewic (1998) obtiveram um índice de clivagem de $91 \%$ dos 149 oócitos selecionados, sendo que destes embriões clivados, $46 \%$ se desenvolveram até o estádio de blastocisto. De nove receptoras transferidas nasceram oito cordeiros (dois embriões transferidos por ovelha).

Baldassarre et al. (1996) em estudo envolvendo três diferentes tratamentos hormonais obtiveram através da LOPU, o desenvolvimento embrionário até o estádio de blastocisto. Os autores obtiveram um índice médio de recuperação de 79,5\%, índice de clivagem de $61 \%$ e alcance no estádio de blastocisto de 17\%. Em números totais, foram 13,2 folículos puncionados por ovelha e 10,5 a média de oócitos recuperados por ovelha. Dos 2,9 embriões clivados por ovelha, 0,8 chegaram ao estádio de blastocisto $(27,6 \%)$.

Kühholzer et al. (1997) utilizaram a LOPU em ovelhas sem tratamento hormonal com 5 repetições em intervalos de uma semana utilizando 17 ovelhas no total. O índice de 
recuperação obtido foi de $67,9 \%$, com média de 6.8 folículos por ovelha, com 4.6 oócitos de média por LOPU.

Stangl et al. (1999) trabalhando com raça produtora de leite, dividiram um lote de 20 animais em 4 grupos, realizaram LOPU uma ou duas vezes por semana com ou sem tratamento hormonal. Obtiveram melhores resultados com LOPU uma vez por semana e com tratamento hormonal. Foram 12,2 folículos por animal por sessão com 7 oócitos por semana por animal. A taxa de recuperação foi de 57,5 \%.

Com ovários de animais adultos e pré-púberes provenientes de abatedouro, Dattena et al. (2000) produziram blastocistos pela maturação, fertilização e cultivo in vitro dos embriões. Dos 450 oócitos recuperados provenientes de ovelhas adultas, 335 clivaram (74,4\%). Dos 118 blastocistos $(35,2 \%)$ obtidos, $50(42 \%)$ foram transferidos a fresco e 68 foram vitrificados. Vinte e cinco receptoras foram utilizadas para TE a fresco obtendo $64 \%$ de prenhez com 20 cordeiros nascidos.

Tervit et al. (1996) comentaram sobre a pressão de vácuo utilizada para punção folicular. Segundo os autores, uma maior pressão promove uma melhor taxa de recuperação, porém afetando a qualidade dos oócitos obtidos em seu trabalho (54\%). Uma menor pressão promoveu maior taxa de desenvolvimento até blastocisto (57\%) em seus melhores resultados, resultando em 1,5 cordeiros nascidos por doadora.

Os autores utilizaram na LOPU uma agulha fina, com vias de diâmetro constante desde a agulha até o tubo de colheita. Foram utilizadas 12 ovelhas com cinco repetições de LOPU cada, em intervalos de uma semana. Divididas em 3 tratamentos hormonais diferentes, obtiveram em seu melhor grupo a média de 16,2 folículos por ovelha por sessão, 6,2 oócitos com taxa de recuperação de $34,9 \%$, com perspectiva de produção de dois blastocistos por ovelha por sessão de LOPU. 
Cognié et al. (2004) comentam sobre as dificuldades da TE convencional e aplicações da FIV em animais pré-púberes, prenhes ou post mortem. Segundo os autores, a LOPU oferece a mesma oportunidade de incremento da produção em pequenos ruminantes, quando se tratando de fêmeas de alto valor e uso de sêmen congelado, quando comparada à técnica de TE convencional. Estes autores ainda fizeram menção ao uso de uma agulha de maior calibre para punção dos oócitos, com uma menor pressão de aspiração e diâmetro fino das vias de ligação entre a agulha e o tubo coletor. Com essa combinação, obtiveram taxa de 50 a $60 \%$ de recuperação com índice satisfatório de evolução de oócitos a blastocisto.

Observadas as variações entre os sistemas de punção folicular em ovinos de cada grupo de pesquisa de diferentes países, Rodrigues et al. (2006) compararam os sistemas entre si, em trabalho realizado com ovários de abatedouro e pequeno grupo utilizando-se da LOPU. Os autores concluíram que a pressão de aspiração e o diâmetro interno das vias de ligação entre a agulha e o tubo de colheita interferem na qualidade do oócito. Agulhas curtas são preferíveis, porém, seu calibre não é fator determinante para a eficiência do processo.

Na Itália, Ptak et al. (1999) através de laparotomia, realizaram punção dos folículos ovarianos (OPU) de vinte ovelhas adultas de diferentes idades em duas sessões de aspiração cada. Com 13 folículos de média por ovelha, obtiveram 11 oócitos (taxa de recuperação 79,5\%). Destes, 9,1 oócitos por ovelha participaram da FIV com taxa de 73,7\% de clivagem. O número de blastocistos por ovelha foi de 2,7 com taxa sobre clivados de $40,5 \%$. Os autores obtiveram $47 \%$ de taxa de prenhez aos 60 dias com 14 cordeiros nascidos em 17 receptoras transferidas. O número de cordeiros nascidos por doadora puncionada foi de 0,8 .

Também na Itália, em trabalho mais recente, Berlinguer et al. (2004), com o uso da laparotomia, realizaram 15, 18 e 16 OPU em três sessões repetidas com 5, 6 e 6 ovelhas adultas, respectivamente. Aderências foram observadas pela repetição da OPU (laparotomia). A média de folículos puncionados por ovelha nos três grupos estudados: controle, doses 
constantes de FSH e doses decrescentes de FSH foram respectivamente, 11, 16,3 e 19,8 folículos por sessão de OPU. A taxa de recuperação de oócitos foi de $91 \%$, 93,2\% e 85,2\%. Destes, foram selecionados para FIV 73,2\%, 89\% e 91,4\%. Nova triagem foi feita após a maturação com $90,9 \%, 85,7 \%$ e $87,7 \%$, respectivamente. A porcentagem de embriões clivados pelo número total de oócitos recuperados foi de 75,2\%, 80,6\% e 83,7\% respectivamente. A porcentagem de embriões que alcançaram o estádio de blastocistos pelo número de embriões clivados foi de $11,8 \%, 25,3 \%$ e $16,3 \%$.

Papadopoulos et al. (2002) utilizando ovários de abatedouro na Irlanda, obtiveram 23 fetos de 35 transferências supostamente transferindo dois embriões por receptora. Martínez et al. (2006) obtiveram, na Argentina, 27 cordeiros nascidos a partir de 64 receptoras transferidas com embriões produzidos in vitro.

Cox e Alfaro (2007), no Chile, realizaram 35 LOPU em 35ovelhas. Obtiveram média de 17,2 folículos puncionados por ovelha com 14,6 (total 512) oócitos de média (taxa de recuperação 85,2\%). Do total de 512 oócitos somente 298 clivaram. Destes, 91 foram cultivados em placa, 182 cultivados no oviduto e 20 foram descartados. Dos cultivados em placa, $56(61,5 \%)$ chegaram ao estádio de blastocisto e, dentre os cultivados in vivo 132 (72.5\%) atingiram este estádio. Dos 188 embriões somados foram selecionados 48 para transferência em 23 receptoras obtendo 18 cordeiros nascidos. O índice de cordeiro nascido por ovelha puncionada foi de 0,5 . Os autores concluem não haver diferença significativa entre o cultivo in vivo e in vitro dos embriões.

Comparando o peso de cordeiros produzidos in vivo e in vitro, Martínez et al. (2006) obtiveram como resultado uma diferença de 2 quilos a mais em média, para os cordeiros produzidos in vitro. Tal fato, apesar de não completamente esclarecido, suspeita-se do sistema de cultivo in vitro como causa. 
Os autores consultados nesta revisão de literatura transferiram seus embriões em estádio de blastocisto ou blastocisto expandido produzidos in vitro, com técnicas idênticas à citadas no capítulo de transferência de embriões in vivo. 


\section{MATERIAL E MÉTODO}

\subsection{Local}

Os animais, tanto receptoras quanto doadoras, foram provenientes da Cabanha Terrauna, no município de Serra Negra-SP, e os procedimentos de aspiração folicular, seleção dos oócitos e a transferência embrionária foram realizados na Central Morro Alto, também no município de Serra Negra - SP.

Os processos de maturação, fertilização e cultivo in vitro dos embriões até dois dias após a FIV foram realizados em local próximo, pelo laboratório de Fertilização In Vitro da In Vitro Brasil Ltda, em Mogi Mirim - SP.

O sêmen utilizado foi colhido e congelado na Caroatá Genética em Gravataí - CE

\subsection{Animais}

As ovelhas doadoras de embrião foram da raça Santa Inês, adultas de dois ou três anos de idade e as receptoras, também da raça Sta Inês ou cruza com raças de lã, adultas com um ou dois anos de idade.

Foram utilizadas nove doadoras, divididas em dois grupos conforme o sêmen congelado utilizado do carneiro A ou B, de forma a interferir o menos possível nos resultados. Os animais foram alojados em duas baias adaptadas para ovinos, onde pernoitaram durante todo experimento. No início da manhã e durante a noite, as ovelhas foram mantidas confinadas recebendo feno de gramínea de Jigs, $350 \mathrm{~g}$ de milho triturado misturado a núcleo mineral $^{15}$ e sal mineral ${ }^{16}$ à vontade. Durante o dia permaneceram em piquetes com gramínea coast-cross. Os oócitos foram identificados na Central Morro Alto e enviados para o

\footnotetext{
${ }^{15}$ Nutron

16 Tortuga
} 
laboratório em estufa com temperatura controlada. Os embriões produzidos retornavam à Central após 3 dias (2dias da FIV), para transferência nas receptoras.

As receptoras permaneceram na Central durante dois meses: fase de adaptação, protocolo hormonal, TE e diagnóstico de gestação. Foram alojadas em galpão à noite e início da manhã, anexo às baias das doadoras. A alimentação foi composta por feno de gramínea de jigs e ração balanceada de farelo de milho, trigo, soja e polpa cítrica misturado a núcleo ${ }^{17}$ e sal mineral ${ }^{18}$ à vontade. Durante o dia permaneciam em piquetes de coast-cross.

\subsection{Equipamentos e Instrumentais}

- $\quad$ Monitor colorido 10 polegadas (Sony)

- Processadora de imagem conjugada com fonte de luz xenon (Asap)

- Micro câmera (Asap)

- Fonte de luz halógena com bomba de ar (Ferrari Medical)

- Cabo de luz

- Óptica de $5 \mathrm{~mm}, 30^{\circ}$ (Asap)

- $\quad$ Trocartes de 5mm (Asap/Stors)

- Pinças laparoscópicas de apreensão e dessecação de 5mm(Asap)

- Bomba de vácuo com pressão controlada (Cook)

- Lupa (Nikon)

- Placa aquecedora (Eletrojet)

- Estufa de transporte com temperatura controlada (WTA)

- Banho-Maria com temperatura controlada

\footnotetext{
${ }^{17}$ Nutron

${ }^{18}$ Tortuga
} 


\subsubsection{Materiais especificos adicionais}

- Cateter urinário para felinos (Tom Cat Catheter 3 1⁄2 Fr, Kendall Sovereign - open end)

- Cateter de Foley n 14

- Sistema de punção folicular laparoscópica (adaptado pelo pesquisador)

- Cabo de ar comprimido

- Maca cirúrgica (2 unidades) para ovinos e caprinos (desenvolvida pelo pesquisador)

\subsection{Instalações (cirúrgicas / manipulação)}

A sala de procedimento foi adaptada e localizou-se inserida no galpão de pernoite das ovelhas doadoras e receptoras (Figura 13). Sua metragem foi estabelecida em $5 \mathrm{~m} \mathrm{x} 4 \mathrm{~m}$ para sala de procedimento cirúrgico e $3 \mathrm{~m}$ x $2 \mathrm{~m}$ para sala de manipulação de oócitos e embriões. Uma janela de vidro separou ambas as salas permitindo comunicação visual.

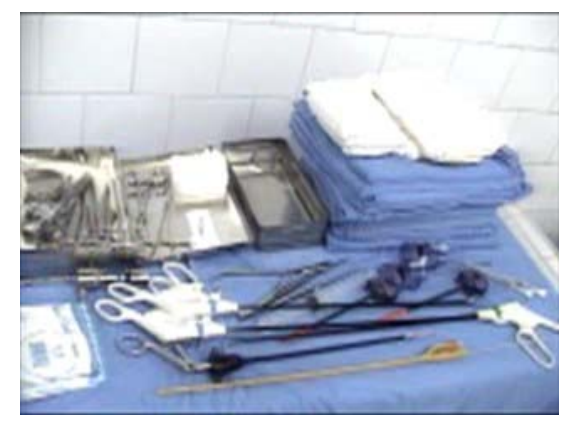

Figura 11 - Imagem digitalizada demonstrando o instrumental cirúrgico utilizado

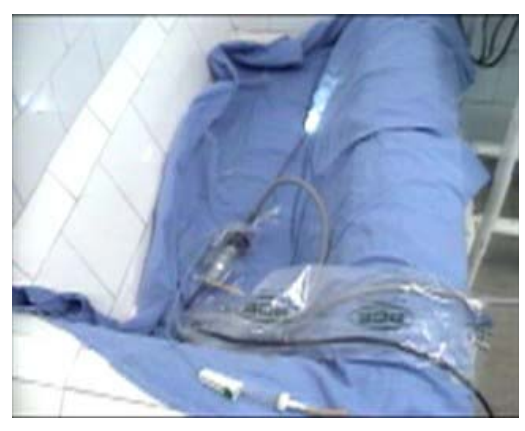

Figura $12-$ Imagem digitalizada demonstrando a óptica acoplada à microcâmera

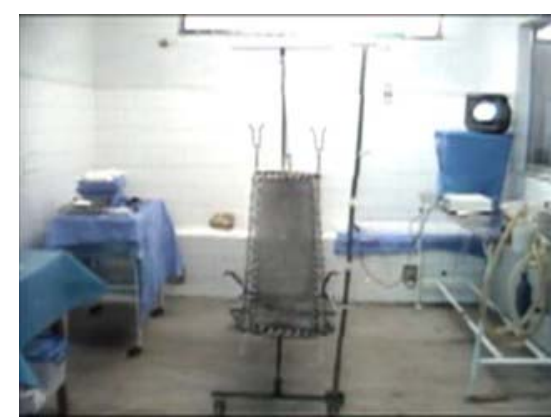

Figura 13 - Imagem digitalizada demonstrando a sala de procedimento cirúrgico com mesa de instrumental e apoio à esquerda, maca cirúrgica ao centro e equipamento de laparoscopia à direita 


\subsection{Tempo de Procedimento}

O tempo de preparo do animal foi computado logo após o início da sedação. O tempo cirúrgico foi computado a partir da primeira incisão de pele até sua síntese.

\subsection{Controle de Gestação}

Realizado através de exame ultra-sonográfico por via transretal após 30 dias das transferências e confirmado a partir dos 60 dias.

\subsection{Delineamento Experimental}

As punções foliculares foram divididas em quatro fases cronológicas, conforme etapa da transferência e diagnóstico de gestação das ovelhas receptoras.

As transferências foram divididas em três fases cronológicas conforme técnica e diagnóstico de gestação das ovelhas receptoras.

- Fase 1 - LOPU + Verificação da viabilidade dos oócitos enviados ao laboratório; avaliação do melhor protocolo anestésico para as receptoras; direcionamento da técnica de TE no oviduto por laparoscopia.

- Fase 2 - LOPU + TE laparoscópica e primeiro diagnóstico de gestação (junho de 2007)

- Fase 3 - LOPU + TE por laparotomia videoassistida e segundo diagnóstico de gestação (julho de 2007)

- Fase 4 - LOPU + TE por laparotomia videoassistida e terceiro diagnóstico de gestação (setembro de 2007)

\subsection{Procedimento Experimental}

\subsubsection{Punção Folicular Laparoscópica (LOPU)}

Foram no total, 37 sessões de LOPU realizadas em 9 ovelhas, sendo que cada ovelha foi puncionada respectivamente $7 x, 6 x, 5 x, 4 x, 4 x, 4 x, 3 x, 3 x$ e $1 x$. O experimento iniciou com número muito pequeno de doadoras sendo que novos animais foram incorporados com o passar do tempo. As doadoras que iniciaram no programa de LOPU permaneceram até a 
última fase sendo puncionadas. Portanto, a ovelha puncionada uma única vez, entrou no último dia das sessões de LOPU.

\subsubsection{Anestesia}

Após serem submetidas a protocolo de superovulação e jejum alimentar de 24 horas e hídrico de 12 horas, as doadoras foram sedadas com xilazina $(0,2 \mathrm{mg} / \mathrm{kg})$ por via intramuscular. Após 10 minutos, foi fixado um cateter na veia jugular e a ovelha colocada na maca cirúrgica em decúbito dorsal. Na seqüência, foi feita a tricotomia e anti-sepsia da região ventral do abdome. A indução anestésica foi realizada com propofol $(5 \mathrm{mg} / \mathrm{kg})$ por via intravenosa seguida de intubação endotraqueal e manutenção com isoflurano.

\subsubsection{Técnica Cirúrgica}

Colocados os panos de campo, a maca foi inclinada em 45 graus com elevação da pelve. Foi feita uma incisão de pele em torno de $0,5 \mathrm{~cm}$ lateral à linha média ventral no lado direito, próxima à glândula mamária, para introdução do primeiro trocarte $(5 \mathrm{~mm})$ (Figura 11) para passagem da óptica (5mm, 30graus) (Figura 12). Atingindo a cavidade abdominal, o abdome foi insuflado com o ar ambiente proveniente da bomba da fonte de luz.

Uma segunda incisão, no lado oposto à primeira, foi realizada para introdução de trocarte $(5 \mathrm{~mm})$ para passagem da pinça de apreensão ovariana. A última incisão foi feita cranial à primeira para introdução de trocarte $(5 \mathrm{~mm})$ para penetração da bainha acoplada à mangueira e agulha de aspiração (Figura 15). O mesmo portal foi utilizado eventualmente para uma segunda pinça de manipulação.

A mangueira foi acoplada em um tubo coletor contendo PBS (Gibco BRL, Life Technologies BV, Breda, The Netherlands) + heparina e este acoplado a uma bomba de vácuo 
(Figura 14). Cada folículo foi puncionado e aspirado individualmente e a lavagem do sistema feita periodicamente ou quando o líquido aspirado apresentasse coloração avermelhada, relativa à presença de sangue. Todos os folículos observados foram puncionados independentemente de seu tamanho ou grau de maturação.

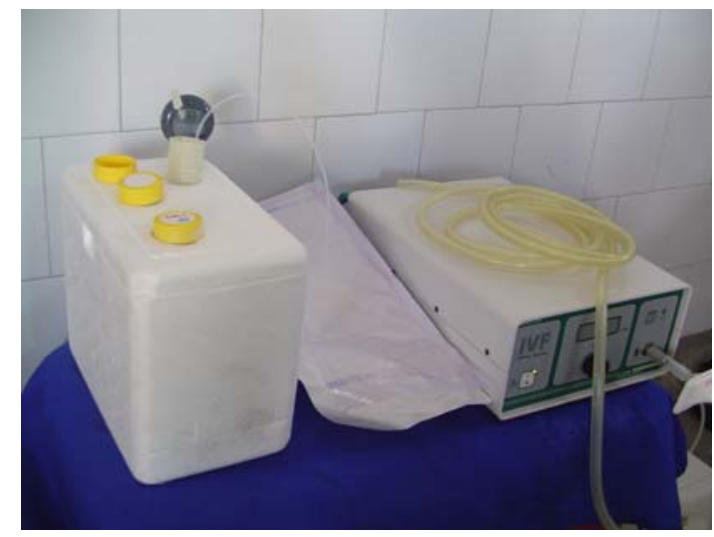

Figura 14 - Imagem digitalizada demonstrando a manutenção do aquecimento do tubo de colheita e meios durante os procedimentos de punção folicular

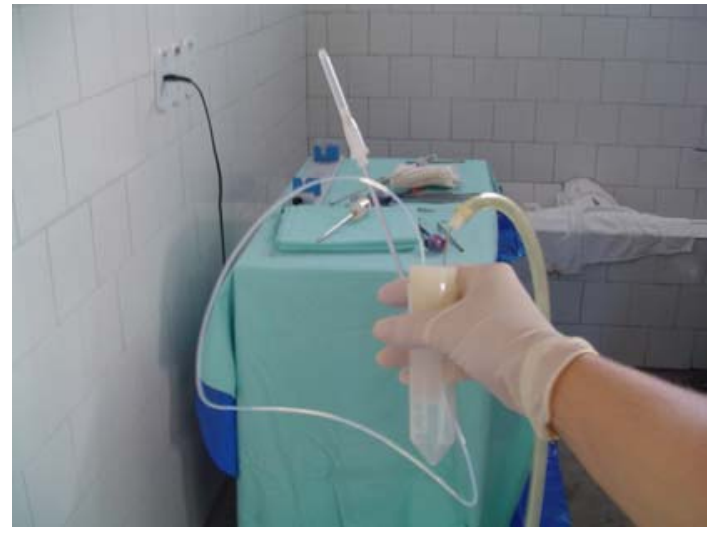

Figura 15 - Imagem digitalizada demonstrando o sistema de punção folicular com agulha protegida por tampa

Ao final, ambos os ovários foram banhados com solução fisiológica e a pele dos três portais suturada em ponto Wolf, com fio nylon 2-0.

$\mathrm{Na}$ seqüência, imediatamente após identificação, todos os oócitos, independentes de sua classificação, foram colocados em meio de maturação e enviados ao laboratório, onde sem exclusão foram submetidos à fertilização.

\subsubsection{Transferência Embrionária (TE)}

\subsubsection{Transporte e recebimento dos embriões}


Os embriões foram transportados do Laboratório para a Central, em estufa de transporte com temperatura controlada. Após a verificação da presença do CL na receptora, os embriões já na sala de manipulação, foram acondicionados no cateter urinário para serem transferidos de imediato.

\subsubsection{Transferência embrionária laparoscópica}

\subsection{Anestesia}

Após serem submetidas a protocolo hormonal de sincronização e jejum alimentar de 24 horas e hídrico de 12 horas, as receptoras foram sedadas com xilazina $(0,2 \mathrm{mg} / \mathrm{kg})$ intramuscular. Dez minutos após, os animais foram colocados na maca cirúrgica em decúbito dorsal para tricotomia e anti-sepsia da região abdominal. A indução anestésica foi realizada com ketamina $(2 \mathrm{mg} / \mathrm{kg})$ e diazepan $(0,2 \mathrm{mg} / \mathrm{kg})$ por via intravenosa, com manutenção através de ketamina (500mg) diluída em solução Ringer (1litro) administrado por via intravenosa a efeito.

\subsection{Técnica Cirúrgica}

Após colocação dos panos de campo, realizou-se uma incisão de pele na linha média ventral, cranial a glândula mamária, para introdução de um trocarte de $5 \mathrm{~mm}$ de passagem à óptica de $5 \mathrm{~mm}, 30^{\circ}$. O segundo portal foi feito cranial ao primeiro e lateral à linha média para passagem de trocarte $(5 \mathrm{~mm})$ (Figura 16) e pinça para manipulação dos ovários, visando a identificação da presença de corpo lúteo (CL). Na ausência do mesmo (Figura 17) o procedimento foi suspenso e uma nova receptora preparada na seqüência. Confirmada a existência do CL (Figura 18), foi inserido mais um trocarte $(5 \mathrm{~mm})$ no lado oposto ao segundo para passagem do cateter de Foley com mandril interno, cuja função após a insuflação de seu 
balão foi auxiliar na exposição e abertura da fímbria, com movimento giratório por debaixo da mesma (Figura 19). Depois de individualizada, uma das fimbrias foi delicadamente elevada utilizando-se da pinça de manipulação. Um cateter intravenoso (16 G) transpassou a pele em local estabelecido de acordo com a localização e direcionamento do oviduto e, no seu interior, foi introduzido um cateter urinário com os embriões no início do oviduto. Em seguida, os instrumentais foram retirados e a pele suturada em ponto Wolf, com fio nylon 2-0.

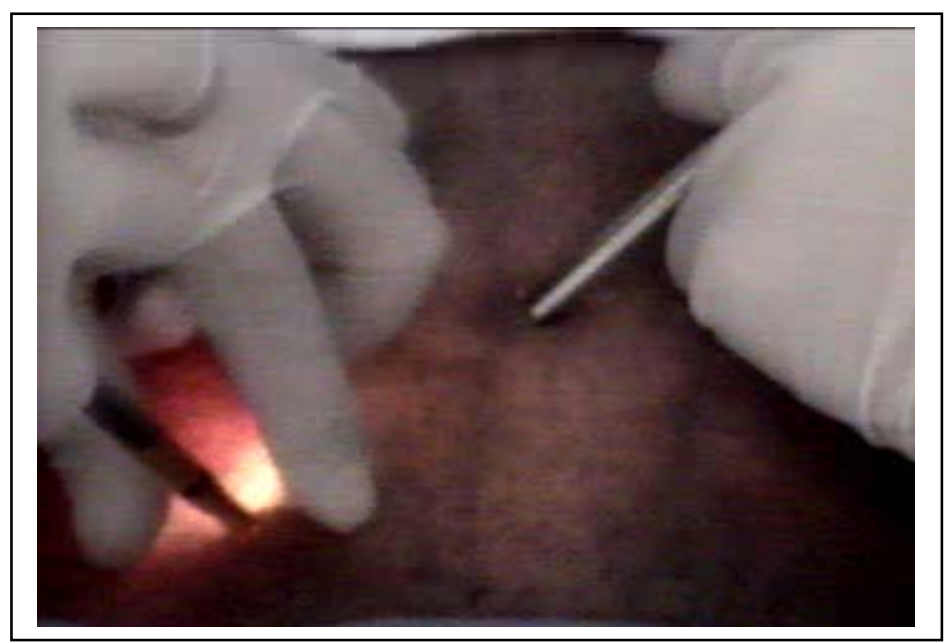

Figura 16 - Imagem digitalizada demonstrando a introdução do segundo trocarte para verificação da presença ou não do $\mathrm{CL}$
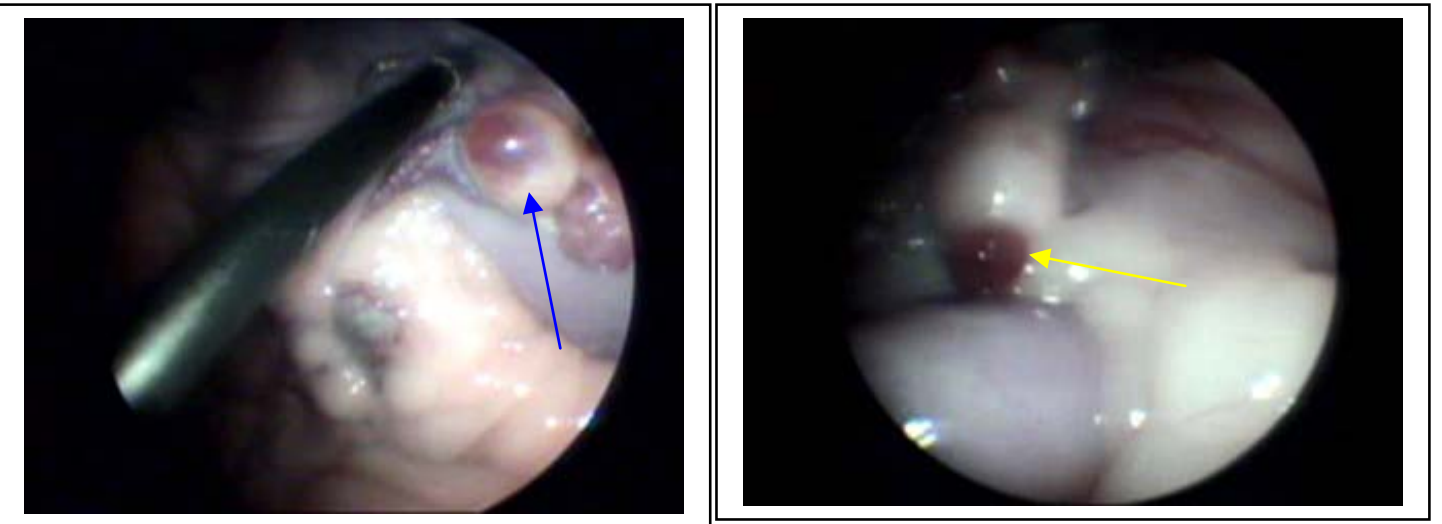

Figuras 17 e 18 - Imagem digitalizada demonstrando um folículo pré-ovulatório (seta azul), e CL (seta amarela) na avaliação laparoscópica para seleção das receptoras. 


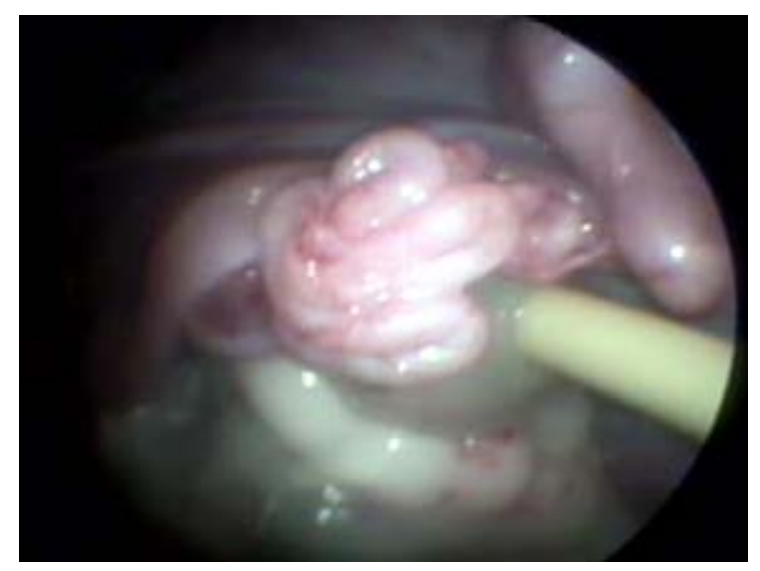

Figura 19 - Imagem digitalizada do posicionamento do cateter de Foley sob o oviduto.

\subsubsection{Transferência embrionária por laparotomia videoassistida}

Para avaliação da presença ou ausência do CL, a laparoscopia foi procedida como descrita anteriormente. Definido o oviduto (direito ou esquerdo) para a transferência, a incisão pela qual entrou o trocarte da óptica foi prolongada (Figura 20). O corno uterino foi pinçado com o auxílio da visão da óptica (Figura 21) e exteriorizado. Deste momento em diante suspendeu-se o uso da óptica.

O corno uterino foi então tracionado até se obter visão das fimbrias que referendam a entrada do oviduto. As fimbrias foram expostas (Figura 22) e uma delas elevada. O cateter urinário foi introduzido por entre as fimbrias para sua penetração no oviduto e aplicação dos embriões.

Após o retorno do útero para cavidade, a musculatura foi suturada em pontos $\mathrm{X}$ fio vicryl 2-0, subcutâneo em ponto simples contínuo fio vicryl 2-0 e pele em ponto Wolf fio nylon 2-0. 


\subsubsection{Pós Operatório}

A recuperação anestésica após os procedimentos foi realizada em piquete plano anexo ao galpão, para na seqüência serem soltos nos piquetes de pastagem. Ao final do dia, os animas receberam metade do concentrado oferecido de rotina e feno à vontade.

Os animais após os procedimentos e nos dias subseqüentes foram observados quanto ao apetite e comportamento no rebanho. A ferida cirúrgica foi observada em dias alternados.

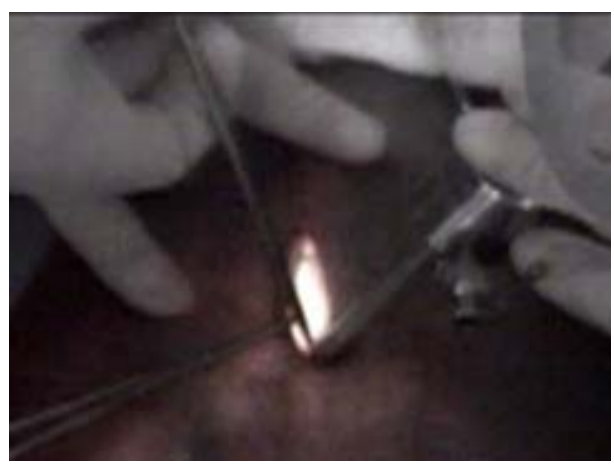

Figura 20 - Imagem digitalizada demonstrando a abertura da incisão abdominal, mantendo-se a óptica em seu posicionamento inicial

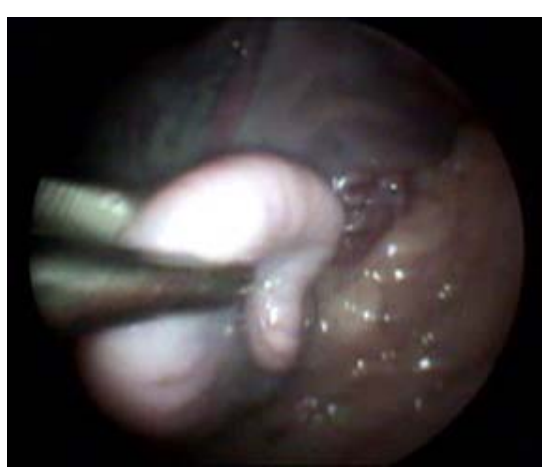

Figura 21 - Imagem digitalizada demonstrando a apreensão videoassistida do corno uterino ipsilateral ao $\mathrm{CL}$

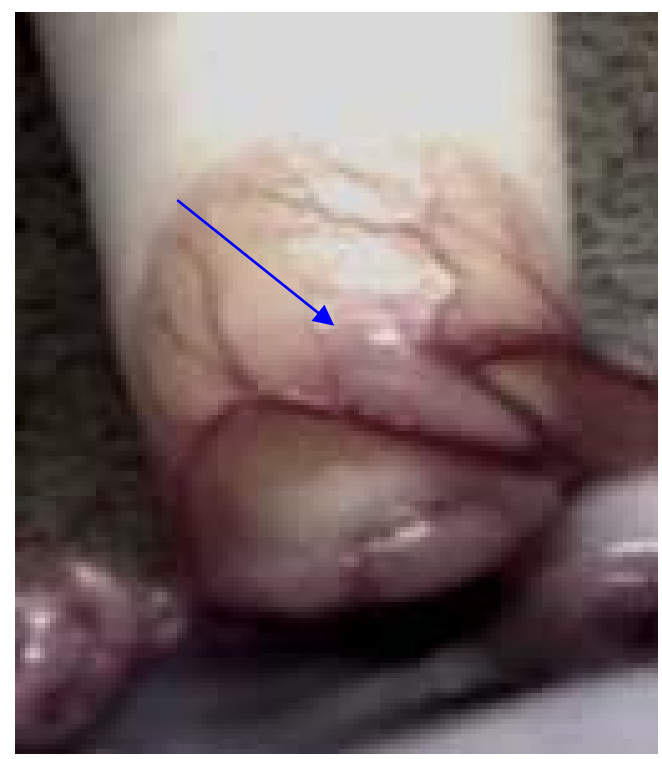

Figura 22 - Imagem digitalizada demonstrando a exposição da fímbria sob a qual referendou-se a entrada do oviduto (seta) 


\subsection{Análise estatística}

Os dados foram analisados através do programa SAS System for Windows (2000). Através do aplicativo Guided Data Analisys, as variáveis quantitativas discretas foram testadas quanto à normalidade dos resíduos e homogeneidade das variâncias. Caso não obedecessem a estas premissas foram transformadas (logarítmo na bas 10 - Log10X; Raiz quadrada - RQX; quadrado - X2) e se a normalidade não fosse obtida, empregava-se então o procedimento NPARIWAY de análise de variância não paramétrica. As variáveis qualitativas binomiais analisadas através do teste Qui-quadrado. Quando as frequências esperadas eram menores que 5 foi utilizado o teste Exato de Fisher.

Para descrição dos resultados das variáveis quantitativas discretas, foram empregados os erros padrões das médias (média +- erro padrão da média) dos dados originais; e os níveis de significância (p) dos dados originais, quando obedecessem às premissas; dos dados transformados, quando nescessária a transformação; e dos dados analisados através da análise não paramétrica, quando não obedecessem às premissas e não houvessem transformações possiveis. As variáveis qualitativas binominais foram descritas através de seu valor em porcentagem, seguido de seus valores absolutos.

O nível de significância utilizado para rejeitar HO (hipótese de nulidade) foi de $5 \%$, ou seja, para um nível de significância menor que 0,05 considerou-se que ocorreram diferenças estatísticas entre as variáveis classificatórias (tratamentos) para uma determinada variável resposta.

As variáveis folículos por LOPU, oócitos resgatados por ovelha por LOPU e fetos por total de receptoras transferidas, obedeceram as premissas, não sendo ncessárias transformações.

As variáveis resposta embriões por LOPU e fetos por sessão de LOPU não obedeceram às premissas, não sendo possível transformá-las. Estas variáveis foram então analisadas através do PROC NPAR1WAY de análise de variância não paramétrica. 


\section{RESULTADOS}

\subsection{Avaliação do semêm}

Não houve diferença estatisticamente significativa $(p>0,05)$ em relação à taxa de clivagem obtida entre os dois semens utilizados.

\subsection{Tempo cirúrgico}

O tempo médio utilizado para os procedimentos de LOPU foi de 35 minutos (30 a 50 min). Para transferência videolaparoscópica foi de 27 minutos (7 a 40 min) e para transferência por laparotomia, 25 minutos (20 a 30min) como representado no Quadro 1. 
Quadro 1 - Representação numérica dos tempos cirúrgicos (minutos) utilizados por receptora na TE por laparoscopia e laparotomia vídeo assistida.

\begin{tabular}{|c|c|c|c|}
\hline \multicolumn{2}{|c|}{ Tempos cirúrgicos da TE laparoscópica } & \multicolumn{2}{|c|}{ Tempos cirúrgicos da TE laparotomia V.A. } \\
\hline Receptora & $\begin{array}{l}\text { Tempo } \\
\text { Cirúrgico (min) }\end{array}$ & Receptora & $\begin{array}{l}\text { Tempo } \\
\text { Cirúrgico (min) }\end{array}$ \\
\hline 1 & 40 & 1 & 35 \\
\hline 2 & 25 & 2 & 30 \\
\hline 3 & 30 & 3 & 30 \\
\hline 4 & 10 & 4 & 25 \\
\hline 5 & 35 & 5 & 30 \\
\hline 6 & 40 & 6 & 30 \\
\hline 7 & 20 & 7 & 25 \\
\hline 8 & 35 & 8 & 25 \\
\hline 9 & 7 & 9 & 30 \\
\hline 10 & 25 & 10 & 25 \\
\hline- & - & 11 & 25 \\
\hline- & - & 12 & 30 \\
\hline- & - & 13 & 35 \\
\hline- & - & 14 & 20 \\
\hline- & - & 15 & 25 \\
\hline - & - & 16 & 20 \\
\hline- & - & 17 & 25 \\
\hline- & - & 18 & 25 \\
\hline- & - & 19 & 25 \\
\hline - & - & 20 & 25 \\
\hline- & - & 21 & 25 \\
\hline- & - & 22 & 25 \\
\hline- & - & 23 & 25 \\
\hline - & - & 24 & 25 \\
\hline- & - & 25 & 20 \\
\hline- & - & 26 & 30 \\
\hline- & - & 27 & 25 \\
\hline- & - & 28 & 30 \\
\hline- & - & 29 & 25 \\
\hline- & - & 30 & 25 \\
\hline- & - & 31 & 25 \\
\hline- & - & 32 & 25 \\
\hline- & - & 33 & 25 \\
\hline- & - & 34 & 25 \\
\hline
\end{tabular}




\subsection{Diagnóstico ultra-sonográfico}

O diagnóstico ultrassonográfico de prenhez foi realizado a partir de trinta e dois dias de gestação. Ao longo do experimento, as ovelhas que receberam embriões foram divididas em três grupos de diagnóstico. O primeiro representa receptoras de embriões transferidos pela técnica de laparoscopia (fase 2) e os dois grupos seguintes, pela técnica de laparotomia(fase 3 e 4).

As fases foram divididas conforme ordem cronológica de tempo, na seqüência em que ocorreram e sua divisão em três, baseada nos 3 dias de diagnósticos. O primeiro dia de diagnóstico de gestação, TE laparoscópica (fase 2) foi realizado junho de 2007. Dentre 10 receptoras avaliadas, 7 apresentaram diagnóstico positivo de prenhez. Na segunda ultrasonografia para diagnóstico de gestação com TE por laparotomia vídeo assistida (fase 3), em julho 2007, de 14 ovelhas avaliadas, 6 apresentaram prenhez positiva. O terceiro diagnóstico de gestação, também com TE por laparotomia (fase 4) foi realizado em setembro 2007 quando, de 20 ovelhas avaliadas, 17 estavam prenhes. Os resultados foram obtidos pela confirmação da prenhez ao exame ultrassonográfico aos 60 dias ou mais de gestação, onde não foram constatadas perdas embrionárias neste período. $\mathrm{O}$ número de fetos por gestação encontra-se descrito posteriormente.

\section{4 Índices obtidos}

A fase 1 como demonstrada no anexo 1, foi utilizada para verificação da viabilidade dos oócitos recuperados e enviados ao laboratório, avaliação de melhor protocolo anestésico 
nas receptoras e direcionamento da técnica de TE no oviduto por laparoscopia. Portanto, a primeira fase com relação à transferência embrionária, não fez parte dos resultados.

Na fase 1, (Tabela 1) foram realizadas um total de 12 sessões de LOPU. O número total de folículos puncionados foi de 124, obtendo-se uma média de 10,3 folículos por sessão de LOPU. Dos 124 folículos puncionados, 88 oócitos foram obtidos (71\% de recuperação), o que representa uma média de 7,3 oócitos por ovelha submetida a LOPU.

$\mathrm{Na}$ fase 2, foram realizadas um total de 8 sessões de LOPU (Tabela 1). O número total de folículos puncionados foi de 62, obtendo-se uma média de 7,8 folículos por LOPU. Dos 62 folículos puncionados foram obtidos 46 oócitos, perfazendo uma taxa de recuperação de $74 \%$. A média final de oócitos por ovelha submetida a LOPU foi de 5,8. Foi utilizado o sêmen de dois carneiros (A e B). O total de embriões produzidos e transferidos dois dias após fecundação foi de 22 (Tabela 2), obtendo-se uma média de 2,8 embriões por sessão de LOPU. O percentual de embriões produzidos em relação à quantidade de oócitos puncionados foi de $48 \%$.

Foram utilizadas para a TE laparoscópica 10 receptoras (Tabela 3), sendo que cada uma delas recebeu uma média de 2,2 embriões (Tabela 3). Sete delas apresentaram prenhez positiva perfazendo $70 \%$ do total de receptoras desta fase. Das sete ovelhas prenhes, 8 fetos foram diagnosticados. Obteve-se, nesta fase 1 feto por sessão de LOPU.

$\mathrm{Na}$ fase 3, da TE por laparotomia, foram realizadas 8 sessões de LOPU (Tabela 1). O número total de folículos puncionados foi de 54, obtendo-se uma média de 6,8 folículos por LOPU. Dos 54 folículos puncionados foram obtidos 50 oócitos, representando uma taxa de recuperação de 93\%. A média de oócitos por ovelha submetida a LOPU, neste caso, foi de 6,3. Foi utilizado o sêmen de 2 carneiros (A e B), sendo um carneiro por repetição. Trinta e dois embriões foram produzidos e transferidos dois dias após fecundação (Tabela 2), obtendo- 
se uma média de 4,0 embriões por sessão de LOPU. O percentual de embriões produzidos em relação à quantidade de oócitos aspirados foi de $64 \%$.

Quatorze receptoras foram utilizadas na fase 3 da TE por laparotomia (Tabela 3), sendo que cada uma delas recebeu uma média de 2,3 embriões. Seis receptoras apresentaram prenhez positiva perfazendo $43 \%$ do total de receptoras desta fase. Das 6 ovelhas prenhes, dez fetos foram diagnosticados. Obteve-se, nesta fase, 1,3 fetos por LOPU.

$\mathrm{Na}$ fase 4, de TE por laparotomia, foram realizadas 9 sessões de LOPU (Tabela 1). O número total de folículos puncionados foi de 80 , obtendo-se uma média de 8,9 folículos por LOPU. Dos 80 folículos puncionados 75 oócitos foram recuperados (taxa de recuperação de 94\%), obtendo-se uma média de 8,3 oócitos por ovelha submetida a LOPU. O total de embriões produzidos e transferidos dois dias após fecundação foi de 57 (Tabela 2), obtendo-se uma média de 6,3 embriões por sessão de LOPU. O percentual de embriões produzidos em relação à quantidade de oócitos aspirados foi de $76 \%$.

Vinte receptoras foram utilizadas na fase 4 ( Tabela 3), sendo que cada uma delas recebeu uma média de 2,9 embriões. Dezessete receptoras apresentaram prenhez positiva perfazendo $85 \%$ do total de receptoras desta fase. Das 17 ovelhas prenhes, 30 fetos foram diagnosticados, totalizando 3,3 fetos por LOPU realizada. 
Tabela 1 - Efeito das fases sobre as variáveis [média (erro padrão da média)] das variáveis média de folículos por sessão de LOPU, taxa de recuperação(Oó/Fol) e média de oócitos por sessão de LOPU

\begin{tabular}{ccccccc}
\hline Fase & LOPU & Fol. Punc & M.Fol/LOPU & Oó & Oó/Fol & M.Oó/LOPU \\
\hline 1 & 12 & 124 & $\begin{array}{c}10,3^{\mathrm{a}} \\
(1,9)\end{array}$ & 88 & $\begin{array}{c}71 \%^{\mathrm{a}} \\
(88 / 124)\end{array}$ & $\begin{array}{c}7,3^{\mathrm{a}} \\
(0,1)\end{array}$ \\
\hline 2 & 8 & 62 & $\begin{array}{c}7,8^{\mathrm{a}, \mathrm{b}} \\
(1,0)\end{array}$ & 46 & $\begin{array}{c}74 \%^{\mathrm{a}} \\
(46 / 62)\end{array}$ & $\begin{array}{c}5,8^{\mathrm{a}} \\
(0,1)\end{array}$ \\
\hline 3 & 8 & 54 & $\begin{array}{c}6,8^{\mathrm{b}} \\
(1,0)\end{array}$ & 50 & $\begin{array}{c}93 \% \%^{\mathrm{b}} \\
(50 / 54)\end{array}$ & $\begin{array}{c}6,3^{\mathrm{a}} \\
(0,1)\end{array}$ \\
\hline 4 & 9 & 80 & $\begin{array}{c}8,9^{\mathrm{a}, \mathrm{b}} \\
(1,1)\end{array}$ & 75 & $\begin{array}{c}94 \% \%^{\mathrm{b}} \\
(75 / 80)\end{array}$ & $\begin{array}{c}8,3^{\mathrm{a}} \\
(0,1)\end{array}$ \\
\hline
\end{tabular}

Valores com letras diferentes na mesma coluna diferem significativamente entre si $(\mathrm{P}<0,05)$

Legenda:

LOPU - Laparoscopic ovum pick-up / punção dos folículos ovarianos

Fol Punc - Folículos puncionados

M.Fol/LOPU - Média de folículos puncionados por LOPU

Oó - Oócitos

Oó/Fol - Taxa de recuperação (total de folículos puncionados / total de oócitos recuperados

M. Oó/LOPU - Média de oócitos recuperados por sessão de LOPU

Tabela 2 - Efeito das fases sobre as variáveis [média (erro padrão da média)] das variáveis taxa de conversão de oócitos em embrião (Emb/ Oó) e média de embrião por sessão de LOPU

\begin{tabular}{cccccc}
\hline Fase & LOPU & Oó & Emb D2 & Emb./Oó & Emb./LOPU \\
\hline 2 & 8 & 46 & 22 & $\begin{array}{c}48 \% \%^{\mathrm{a}} \\
(22 / 46)\end{array}$ & $\begin{array}{c}2,8^{\mathrm{b}} \\
(0,8)\end{array}$ \\
\hline 3 & 8 & 50 & 32 & $\begin{array}{c}64 \%^{\mathrm{a}, \mathrm{b}} \\
(35 / 50)\end{array}$ & $\begin{array}{c}4,0^{\mathrm{ab}} \\
(0,9)\end{array}$ \\
\hline 4 & 9 & 75 & 57 & $\begin{array}{c}76 \% \%^{\mathrm{b}} \\
(57 / 75)\end{array}$ & $\begin{array}{c}6,3^{\mathrm{a}} \\
(1,0)\end{array}$
\end{tabular}

Valores com letras diferentes na mesma coluna diferem significativamente entre si $(\mathrm{P}<0,05)$.

Legenda:

Oó - oócitos

Emb. D2 - total de embriões clivados produzidos (dia 2 pós fecundação)

Emb. / Oó - Taxa de conversão de oócitos para embrião

Emb/LOPU - Média de embriões clivados produzidos por sessão de LOPU 
Tabela 3 - Efeito das fases sobre as variáveis [média (erro padrão da média)] das variáveis taxa de prenhez (número de receptoras prenhes sobre número de receptoras transferidas), média de fetos por sessão de LOPU, total de fetos por total de receptoras transferidas.

\begin{tabular}{|c|c|c|c|c|c|c|c|}
\hline Fase & LOPU & Emb/Rec & No Rec & $\mathrm{P}+/ \operatorname{Rec}$ & Fetos & M.Fetos/LOPU & Fetos/Rec \\
\hline 2 & 8 & 2,2 & 10 & $\begin{array}{c}70 \%^{a, b} \\
(7 / 10)\end{array}$ & 8 & $\begin{array}{l}1,0^{b} \\
(0,3)\end{array}$ & $\begin{array}{c}80 \%{ }^{a b} \\
(8 / 10)\end{array}$ \\
\hline 3 & 8 & 2,3 & 14 & $\begin{array}{c}43 \% \%^{a} \\
(6 / 14)\end{array}$ & 10 & $\begin{array}{l}1,3^{b} \\
(0,7)\end{array}$ & $\begin{array}{l}71 \% \mathrm{~b} \\
(10 / 14)\end{array}$ \\
\hline 4 & 9 & 2,9 & 20 & $\begin{array}{l}85 \% \mathrm{~b} \\
(17 / 20)\end{array}$ & 30 & $\begin{array}{l}3,3^{a} \\
(0,6)\end{array}$ & $\begin{array}{c}150 \%{ }^{a} \\
(30 / 20)\end{array}$ \\
\hline
\end{tabular}

Valores com letras diferentes na mesma coluna diferem significativamente entre si $(\mathrm{P}<0,05)$.

Legenda:

LOPU - laparoscopic ovum pick-up / punção dos folículos ovarianos

$\mathrm{Emb} / \mathrm{Rec}$ - média de embriões transferidos por receptora

No Rec - Número de receptoras utilizadas na fase

$\mathrm{P}+/ \mathrm{Rec}$ - Taxa de prenhez - total de receptoras prenhes sobre o total de receptoras transferidas

M.Fetos / LOPU - Média de fetos por sessão de LOPU

Fetos / Rec - número total de fetos diagnosticados por total de receptoras transferidas

\subsection{Complicações}

Não foi observada a presença de infecção ou dor perceptível por alteração de comportamento decorrente dos procedimentos, tanto na LOPU quanto na transferência embrionária por laparoscopia ou laparotomia, apesar da ausência do uso de antiinflamatórios ou antibióticos.

As feridas cirúrgicas foram observadas diariamente e não houve necessidade de curativo nos dias subseqüentes aos procedimentos, como também não foi observada perda do apetite após três horas de intervenção.

Apesar das sessões consecutivas de LOPU na mesma doadora $(7 \mathrm{x}, 6 \mathrm{x}, 5 \mathrm{x}, 4 \mathrm{x}, 4 \mathrm{x}, 4 \mathrm{x}$, $3 x, 3 x$ e $1 x)$, não foram diagnosticadas aderências com exceção a uma ovelha que, em sua última sessão $\left(6^{\mathrm{a}}\right)$, apresentou pequena ligação entre a fímbria e o ovário, o que não prejudicou a visão de toda sua superfície ou a punção dos folículos existentes. Todas as 
ovelhas que iniciaram nas sessões de LOPU continuaram sendo puncionadas até o final do experimento.

Uma das receptoras sofreu uma parada respiratória após a indução anestésica. O procedimento foi suspenso e a ovelha se recuperou nos minutos seguintes.

Durante a introdução do primeiro trocarte (descartável, não sendo recomendada sua reutilização) em uma das receptoras, houve uma falha no mecanismo de segurança do mesmo, lacerando a bexiga. Imediatamente foi inserido mais um trocarte crânio-lateralmente ao primeiro para introdução de pinça de apreensão, para o fechamento provisório dos bordos da laceração impedindo o extravasamento de mais urina na cavidade. Após avaliação do quadro, optou-se por sutura da bexiga em plano único, ponto Lembert, por via laparoscópica, com a inserção de mais um trocarte. Tal procedimento teve duração de 15 minutos. A ovelha foi observada durante uma semana sem apresentar alterações de comportamento. Após 60 dias retornou ao programa de transferência e foi diagnosticada com prenhez positiva.

Uma ovelha receptora regurgitou durante o procedimento de transferência após a implantação de dois embriões. Na recuperação anestésica, percebeu-se uma forte dispnéia, que se manteve com o animal já em estação indicativa de falsa via, vindo a óbito em intervalo de 30 minutos. Imediatamente foi realizada nova "laparotomia" para retirada do oviduto, desde sua porção inicial até a junção útero-tubárica. $\mathrm{O}$ interior do oviduto foi lavado no sentido uterino em uma placa de Petri, onde foram encontrados os dois embriões juntamente com mais dois oócitos. Os dois embriões foram transferidos em outra receptora, a qual, posteriormente, teve diagnóstico confirmado de prenhez de um feto. 


\section{DISCUSSÃO}

A sala onde os procedimentos foram realizados, localizada internamente no galpão de permanência dos animais, colaborou com a diminuição do estresse no período pré-operatório e após os procedimentos. Tal fato foi verificado através da ausência de berros e tranqüilidade dos animais. Por outro lado, uma boa vedação e facilidade de higienização, tanto da área destinada aos procedimentos cirúrgicos, quanto de manipulação dos embriões foram de grande importância. O tamanho das instalações cirúrgicas e de manipulação como descrito anteriormente não prejudicou o bom andamento dos procedimentos; pelo contrário, facilitou a mão de obra gasta na sua desinfecção. A porta de entrada bastante ampla proporcionou boa circulação das macas e equipe.

Um fator importante com a utilização do vídeo é a luminosidade. A pouca abertura para penetração de luz natural e a mesma situada por de trás do monitor, proporcionou a ausência de reflexo luminoso na superfície da tela, o que supostamente dificultaria a visão da imagem.

O posicionamento dos equipamentos de laparoscopia e instrumentais cirúrgicos dispostos em lados opostos da maca, (Figura 23) transmitiu segurança, diminuindo riscos de acidentes com equipamento. O mesmo foi observado com o local de descanso da óptica (Figura 12).

A localização do monitor à frente do cirurgião privilegiou sua manipulação, porém, prejudicou o conforto cirúrgico do auxiliar da câmera. Um melhor posicionamento do monitor seria ao alto e por de atrás da ovelha, entre os dois operadores, o que raramente é possível em condições a campo.

A maca cirúrgica foi considerada adequada aos procedimentos, pela facilidade e simplicidade de contenção do animal e regulagem em vários níveis de inclinação. A 
versatilidade de sua movimentação possibilitou rápida troca de animais entre os procedimentos. Foram isolados os membros posteriores do animal com panos de campo, possibilitando o apoio aos cabos da óptica. Isto facilitou a manutenção da anti-sepsia, ao mesmo tempo em que impediu uma queda acidental da óptica. A largura, altura e comprimento da maca proporcionaram conforto aos animais e a ambos os operadores para o trabalho em pé. A comunicação visual entre as salas permitiu (Figura 24) a sincronia entre o preparo do embrião e sua transferência.

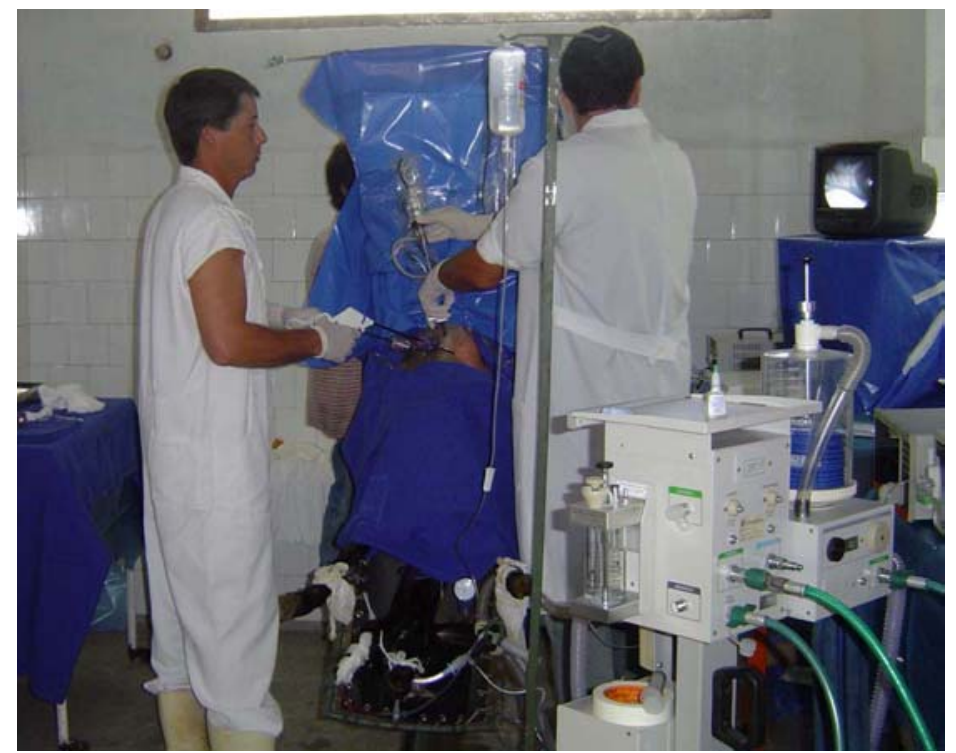

Figura 23 - Imagem digitalizada demontrando a utilização da sala de procedimento cirúrgico.

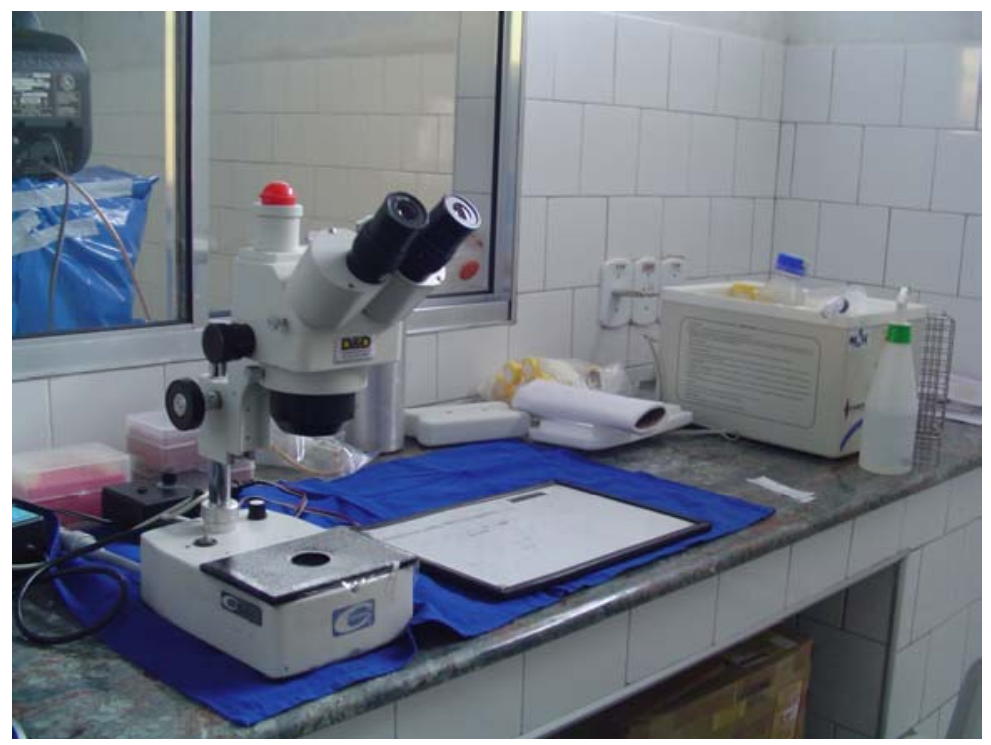

Figura 24 - Imagem digitalizada demonstrando a sala de manipulação de oócitos e embrião e sua comunicação visual com a sala de procedimento. 
O jejum hídrico e alimentar foi considerado satisfatório pela ausência de dilatação de alças intestinais verificadas durante a laparoscopia. Alguns animais regurgitaram durante o procedimento, por causas não bem estabelecidas.

O protocolo anestésico realizado nas doadoras foi considerado seguro, e não interferiu no bom andamento dos procedimentos; ao contrário, o protocolo instituído para as receptoras, aumentou a freqüência respiratória em alguns animais, dificultando o realizar da técnica. A intubação traqueal proferida nas doadoras, eliminou o risco de falsa via por refluxo. Partindose da posse do aparelho, o custo com a anestesia inalatória realizada nas doadoras, foi menor quando comparado à anestesia intravenosa realizada nas receptoras, porém, somando-se a recarga do cilindro de oxigênio os custos se equipararam.

A técnica de LOPU inicialmente descrita por Baldassarre et al. (1994) foi utilizada com sucesso no presente trabalho com algumas modificações. A primeira foi o uso da microcâmera acoplada ao monitor (ALBERIO et al., 2002), que proporcionou uma boa qualidade de imagem, não só pela nitidez com a qual os folículos ovarianos foram detectados, como também pela magnificação da imagem obtida.

A possibilidade de se trabalhar com um auxiliar na câmera disponibilizou ambas as mãos do cirurgião para manipulação dos ovários concomitante à punção dos folículos, permitindo o ajuste do melhor ângulo de penetração da agulha de punção.

Uma segunda modificação na técnica de Baldassarre et al. (1994) foi realizada no sistema de punção; com diâmetro constante desde a saída da agulha até o tubo de colheita eliminando conexões (RODRIGUEZ et al., 2006). Porém, a possibilidade de visão interna do sistema por via laparoscópica foi mantida (BALDASSARRE et al., 1994).

A utilização de trocarte permanente com sistema de segurança em sua extremidade eliminou com sucesso, a insuflação do abdome com a agulha de Veress previamente à introdução do primeiro trocarte, como também constatado em eqüinos (TABET, 2003). 
A taxa de recuperação média (oócitos recuperados por folículos puncionados), verificada neste estudo $(71 \%, 74 \%, 93 \%$ e $94 \%)$ foi similar às melhores médias obtidas em outros estudos com LOPU $(31 \%, 80 \%$ e $85 \%$ ) (ALBERIO et al., 2002; BALDASSARRE et al., 1996; COX; ALFARO, 2007) respectivamente. A semelhança com a técnica inicialmente descrita, com as respectivas modificações instituídas, foram as possíveis causas dos índices encontrados.

Houve uma melhora significativa $(\mathrm{p}<0,05)$ nas taxas de recuperação entre as primeiras e ultimas sessões de LOPU. Tal fato ocorreu devido ao treinamento e entrosamento da equipe cirúrgica. Como desvantagem, o auxiliar câmera, com o uso da vídeolaparoscopia, atua ativamente nos procedimentos, sendo de suma importância um treinamento adequado para seu bom desempenho.

Apesar da maior eficiência cirúrgica com o uso do vídeo, deve-se ponderar seu uso em procedimentos mais simples e realizados a campo, onde são utilizados somente dois portais de acesso.

Por sua vez, o número de folículos puncionados por sessão de LOPU (10,3, 7,8, 6,8 e $8,3)$ foi menor que a média encontrada na literatura consultada $(19,8,17,2,12,2$ e 6,8$)$ (BERLINGUER et al., 2004; COX; ALFARO, 2007; STANGL et al., 1999; KÜHHOLZER et al., 1997). No presente estudo, houve diferença significativa $(\mathrm{p}<0,05)$ entre o número de folículos por sessão entre as fases 1 e 3. A impossibilidade da realização de flushing alimentar nas doadoras foi uma das prováveis causas, pois as mesmas apresentavam-se obesas antes do início do programa. A média inferior de folículos totais também pode estar relacionada ao protocolo hormonal instituído (BERLINGUER et al., 2004), porém o estudo não objetivou a avaliação de protocolos hormonais que supostamente aumentassem os números de folículos por doadora. A simplicidade na aplicação e as baixas dosagens foram os quesitos que levaram à escolha do protocolo. 
A época do ano pode interferir na quantidade de folículos produzidos, (ANEL et al. 2005), porém, não foi levada em consideração para realização deste estudo, com utilização de uma raça supostamente não estacional, o que teoricamente minimizou tais efeitos neste trabalho. Contudo, o baixo número de folículos foi compensado pelas altas taxas de recuperação, obtendo-se números razoáveis de oócitos por sessão de LOPU $(7,3,5,8,6,3$ e 8,3) quando comparada a outros estudos (ALBERIO et al., 2002) com boa produção folicular de seus animais, porém com baixas taxas de recuperação (16 folículos puncionados e 6,2 oócitos recuperados por sessão de LOPU).

A qualidade dos oócitos foi verificada na avaliação dos embriões clivados produzidos em relação ao número de oócitos recuperados $(48 \%, 64 \%$ e $76 \%)$ quando comparados à literatura consultada (57\%, 58\% e 61\%), (TERVIT et al., 1995; COX; ALFARO, 2007; BALDASSARRE et al., 1996). Deve-se também ser levada em consideração a eficiência do laboratório na produção dos embriões. Creditam-se as melhoras estatisticamente significativas $(\mathrm{p}<0,05)$ das taxas de clivagem acima citadas, à técnica de fertilização in vitro e à melhoria no desenvolvimento da técnica de LOPU.

O tempo médio de procedimento cirúrgico, para realização das LOPU foi de 35 minutos, com variação entre 30 e 50 minutos, considerado satisfatório para a técnica, quando se objetiva a punção de todos os folículos existentes como foi o caso deste trabalho. A ausência de intercorrências anestésicas proporcionou tranqüilidade aos procedimentos. Em alguns animais, houve uma falha no sistema de aspiração por obstrução da agulha com coágulos de sangue, o que aumentou o tempo cirúrgico em alguns casos. Outro fator que contribuiu para demora em alguns procedimentos foi a dificuldade em manutenção do pneumoperitônio. Promovendo a solução de ambos os problemas acima citados, somando-se ao treinamento continuado tanto do cirurgião quanto do auxiliar câmera, há possibilidade de diminuição do tempo cirúrgico. 
Com relação às aderências, não foram observadas mesmo após as sucessivas sessões de LOPU na mesma doadora $(7,6,5,4,4,4,3,3$ e 1), corroborando com os resultados de diferentes estudos (SNYDER; DUKELOW, 1974; BALDASSARRE et al., 1996; KÜHHOLZER et al., 1997; ALBERIO et al., 2002) e divergindo do que foi relatado por Berlinguer et al., (2004) e Cognié et al. (2004) referindo-se às aderências ocasionadas pela laparotomia na OPU ou à exposição dos cornos uterinos na técnica de TE convencional respectivamente.

Com relação aos tempos de cirurgia para TE, foi observado uma homogeneidade na duração dos procedimentos realizados por técnica de laparotomia (20 a 30min), o que não ocorreu com a transferência por técnica laparoscópica (7 a 40 min). Este fato ocorreu devido à dificuldade na introdução dos embriões por entre as fimbrias que por sua vez sofreu influência de vários fatores: diferença anatômica entre as receptoras, relativa ao sentido da entrada do oviduto, impossibilitando a previsão do melhor posicionamento dos trocartes e cateter, para introdução dos embriões; comprimento curto em alguns casos do cateter contendo os embriões para transferência; elevação na freqüência respiratória da receptora; inexperiência na manipulação do oviduto por via laparoscópica tanto do cirurgião quanto do auxiliar câmera. Por outro lado, o tempo cirúrgico foi muito menor em alguns animais, quando comparado ao menor tempo da laparotomia. Neste caso, houve menos influência dos fatores acima citados.

Um aumento na longevidade das receptoras (SCHIEWE et al., 1984), também foi observado neste trabalho quando utilizada técnica laparoscópica para transferência dos embriões no oviduto, possibilitando a reutilização das receptoras prenhes e de boa habilidade materna.

A busca na redução do estresse cirúrgico e pós-operatório imediato foi motivação para este estudo com o desenvolvimento da TE laparoscópica. O argumento citado na revisão de 
literatura, referente à diminuição da taxa de prenhez com IATC, por ativação hormonal ou de substâncias como prostaglandinas e corticosteróides endógenos prejudiciais ao desenvolvimento embrionário, decorrente aos danos causados na tração e transposição da cérvix pode, nas devidas proporções, justificar uma diminuição das taxas de prenhez, relacionada com a tração e manipulação do útero necessária para TE FIV no oviduto por laparotomia.

Diante da impossibilidade de previsão do número de embriões clivados por ovelha puncionada, antes da sincronização das ovelhas receptoras, o número de embriões transferidos por receptora variou entre as três fases da TE $(2,2,2,3$ e 2,9). Quatro ou três receptoras, em média, foram sincronizadas por doadora puncionada, sendo que uma pequena parcela destas receptoras não apresentou CL, sendo substituídas no momento da transferência. Assim sendo, houve um aumento no número de embriões transferidos na fase 4 da laparotomia, pelo aumento do número de embriões por LOPU proporcionado nesta fase $(6,3)$, quando comparado às demais fases $[2,8(\mathrm{p}<0,05)$ e $4,0(\mathrm{p}>0,05)]$.

Houve diferença estatisticamente significativa $(p<0,05)$ entre os valores obtidos de diagnóstico de prenhez positiva por quantidade de receptora transferida, entre as fases 3 e 4 , da TE por laparotomia, respectivamente (43\% e $85 \%$ ). Parte desta diferença pode ser atribuída ao menor número de embriões transferidos por receptora na fase 3. Por outro lado, a média de embriões transferidos por receptora na TE laparoscópica (fase 2) foi muito semelhante à fase 3 da laparotomia (respectivamente, 2,2 e 2,3), entretanto apesar de não estatisticamente significativa $(\mathrm{p}>0,05)$, a taxa de prenhez obtida com a TE laparoscópica foi superior à fase 3 da TE por laparotomia (respectivamente, 70\%, 43\%). Comparando, apesar de não estatisticamente significativa $(\mathrm{p}>0,05)$, a taxa de prenhez obtida com a TE laparoscópica (70\%) com a fase 4 (TE por laparotomia) (85\%), e supondo médias iguais de embriões 
implantados por receptora em ambas as técnicas, não há diferença numérica quanto às taxas de prenhez observadas.

As taxas de prenhez obtidas neste estudo $(70 \%, 48 \%$ e $85 \%)$ foram maiores quando comparadas às médias dos trabalhos consultados $(47 \%, 64 \%, 38 \%$ e $62 \%)$ respectivamente, (PTAK et al., 1999; DATTENA et al., 2000; MARTÍNEZ et al., 2006; GARDNER et al., 1994), apesar da transferência dos embriões ter sido realizada no estádio de recém clivados. Não pôde ser considerada como termo de comparação, a taxa de prenhez $(82,6 \%)$ apresentada por Cox e Alfaro (2007), em virtude da intensa seleção realizada desde os oócitos recuperados até os blastocistos transferidos.

Quando comparadas, médias de fetos por receptora encontradas neste estudo (48/44), somando todos os fetos diagnosticados de todas as receptoras transferidas, tanto na TE por laparoscopia (fase 2) como nas fases 3 e 4 da laparotomia (8/10, 10/14 e 30/20), com os resultados obtidos por outros autores (BROWN; RADZIEWIC, 1998; COX; ALFARO, 2007; THOMPSON et al., 1995; DATTENA et al., 2000; PTAK et al., 1999; MARTÍNEZ et al., 2006) $(8 / 9,18 / 23,18 / 29,20 / 25,14 / 17$ e 27/64 respectivamente), foi observado que não existem casos onde o número de fetos supera o número de receptoras transferidas como o ocorrido no presente estudo.

A maioria dos trabalhos consultados tiveram por base a transferência de 2 ou eventualmente 3 embriões por receptora, o que obviamente interfere no número de fetos existentes. Porém, o fato da média de embriões transferidos neste estudo ser de 2,5, demonstra que os resultados obtidos neste trabalho, se assemelham aos melhores índices descritos na literatura. Diferença estatisticamente significativa $(p<0,05)$ foi encontrada entre as fases 3 e 4 da TE por laparotomia com relação ao número total de fetos por número de receptoras transferidas, em parte pelo menor número de embriões transferidos na fase 3. 
Não houve diferença estatística $(p>0,05)$ na taxa de conversão de embriões para fetos entre as três fases, o que pressupõe não haver influência da técnica utilizada para TE ou da sua melhoria ao longo do experimento. Do mesmo modo, embora a taxa de clivagem dos embriões tenha aumentado com o passar do tempo, como descrito anteriormente, parece não ter influenciado nesta conversão.

A média de fetos obtida por sessão de LOPU, por sua vez, está diretamente relacionada ao número de folículos produzidos pelas ovelhas doadoras. Porém, também sofreu influências de outros fatores relativos a LOPU já mencionados. Houve taxas superiores ( $\mathrm{p}<$ 0,05) obtidas quanto à média de fetos diagnosticados por sessão de LOPU na fase 4 da laparotomia $(3,3)$, quando comparadas às demais fases $(1,0$ e 1,3).

Devemos ressaltar neste item, o fato de se ter trabalhado com embriões clivados, portanto mais jovens quando comparados aos embriões transferidos em estádio de blastocisto, como é o caso da totalidade dos autores consultados (TERVIT et al., 1996; PTAK et al., 1999; COX; ALFARO, 2007), que obtiveram as seguintes médias (respectivamente, 1,5, 0,8 e 0,5)..

Segundo alguns autores (TERVIT et al., 1996; PTAK et al., 1999; COX; ALFARO, 2007; MARTÍNEZ et al., 2006), somente 30 a 40\% dos embriões clivados chegam ao estádio de blastocisto em cultivo in vitro. Neste estudo, foi possível atribuir às excelentes taxas obtidas em relação à média de fetos por sessão de LOPU (respectivamente, 1, 1,3 e 3,3, com média de 1,9) mesmo após uma série de repetições na mesma doadora, também ao aumento na taxa de desenvolvimento dos embriões clivados transferidos no oviduto para subseqüente desenvolvimento in vivo, quando comparados aos cultivados in vitro até o estádio de blastocisto.

Cox e Alfaro (2007) compararam o desenvolvimento de embriões fertilizados in vitro, clivados e desenvolvidos até o estádio de blastocisto in vitro ou in vivo, concluíram não haver diferença sobre a sobrevivência embrionária entre as duas técnicas. 
Um fator importante que deve ser levado em consideração, quando comparados os resultados entre as médias de fetos nascidos do presente trabalho com os demais autores (TERVIT et al., 1996; PTAK et al., 1999; COX; ALFARO, 2007) é que o parto de uma parcela das receptoras transferidas está previsto para janeiro de 2008, dois meses da presente data. Considerando que há uma porcentagem de perdas, após o diagnóstico de prenhez com sessenta dias de gestação, tanto em decorrência de abortos como perda da receptora por fatores diversos (PTAK et al., 1999; COX; ALFARO, 2007; MARTÍNEZ et al., 2006; DATTENA et al., 1999), calcula-se que cerca de $14 \%(15 \%, 6 \%, 12 \%$ e $20 \%$, respectivamente dos autores citados) dos fetos diagnosticados não venham a termo. Admitindo-se esta porcentagem de perda, provavelmente os resultados deste estudo ficarão em torno de 1.6 cordeiros nascidos por sessão de LOPU.

Foi observado por este trabalho, que através de um manejo adequado das doadoras, proporcionando um aumento no número de folículos produzidos, bem como a continuidade na realização da técnica em equipe, acredita-se poder aumentar o número de cordeiros nascidos por sessão de LOPU através da FIV. 


\section{CONCLUSÃO}

Os bons resultados de desenvolvimento embrionário obtido, tanto na transferência videolaparoscópica quanto por laparotomia videoassistida, em conjunto com a possibilidade de repetições das punções foliculares no mesmo animal, proporcionada pela laparoscopia, foram dados encorajadores à continuidade do aperfeiçoamento da técnica para produção, ainda mais efetiva, de cordeiros fertilizados in vitro. 


\section{REFERÊNCIAS}

ALBERIO, R.; OLIVERA, J.; ROCHE, A.; ALABART, J.; FOLCH, J. Performance of a modified ovum pich-up system using three different FSH stimulation protocols in ewes.

Small Ruminant Research, v. 46, n. 2-3, p. 81-87, 2002.

AMIRIDIS, G. S.; KUEHHOLZER, B.; BESENFELDER, U.; LYMBEROPOULOS, A.; VAINAS, E. Laparoscopic collection and transfer of Chios sheep embryos. Bulletin of the Hellenic Veterinary Medical Society, v. 50, n. 3, p. 244-249, 1999.

ANEL, L.; ALVAREZ, M.; MARTINEZ-PASTOR, F.; GARCIA-MACIAS, V.; ANEL, E.; PAZ, P. Improvement strategies in ovine artificial insemination. Reproduction Domestic Animals, v. 41, n. S2, p. 30-42, 2006. Supplement 2.

ANEL, L.; KAABI, M.; ABROUG, B.; ALVAREZ, M.; ANEL, E.; BOIXO, J. C.; FUENTE, L. F.; PAZ, P. Factors influencing the success of vaginal and laparoscopic artificial insemination in churra ewes: a field assay. Theriogenology, v. 63, n. 4, p. 1235-1247, 2005.

ANEL, L.; SEVILLANO, C.; ALVAREZ, M.; ALEGRE, B.; ANEL, E.; DOMÍNGUEZ, J. C.; CARBAJO, M. T.; DE LA FUENTE, J. Repeated laporoscopic follicular aspiration in lambs. Theriogenology, v. 47, n. 1, p. 152, 1997.

ARMSTRONG, D. T.; EVANS, G. Factors influencing success of embryo transfer in sheep and goats. Theriogenology, v. 19, n. 1, p. 31-42,1983.

ARNDTBIRKENHOF, M. Die künstliche besamung der ziege. [S. 1.: s. n.], [2004?]. Curso de Inseminação Cervical em Ovelhas e Cabras.

BALDASSARRE, H.; FURNUS, C. C.; MATOS, D. G.; PESSI, H. In vitro production of sheep embryos using laparoscopic folliculocentesis: alternative gonadotrophin treatments for stimulation of oocyte donors. Theriogenology, v. 45, n. 3, p. 707-717, 1996.

BALDASSARRE, H.; KARATZAS, C. N. Advanced assisted reproduction technologies (ART) in goats. Animal Reproduction Science, v. 82-83, p. 255-266, 2004.

BALDASSARRE, H.; MATOS, D. G.; FURNUS, C. C.; CASTRO, T. E.; CABRERA FISCHER, E. I. Technique for efficient recovery of sheep oocytes by laparoscopic folliculocentesis. Animal Reproduction Science, v. 35, n. 1-2, p. 145-150, 1994. 
BARI, F.; KHALID, M.; WOLF, B.; HARESIGN, W.; MURRAY, A.; MERRELL, B. The repeatability of superovulatory response and embryo recovery in sheep. Theriogenology, $\mathrm{V}$. 56 , n. 12, p. 147-155, 2001.

BERLINGUER, F.; LEONI, G.; BOGLIOLO, L.; PINTUS, P. P.; ROSATI, I.; LEDDA, S.; NAITANA, S. FSH different regimes affect the developmental capacity and cryotolerance of embryos derived from oocytes collected by ovum pick-up in donor sheep. Theriogenology, v. 61, n. xx, p. 1477-1486, 2004.

BICUDO, S. D.; AZEVEDO, H. C.; MAIA, S. M.; GREEN, R. E.; RODELLO, L.; MEIRA, C. Avanços na criopreservação do sêmen ovino visando sua aplicação em programas de inseminação artificial e em biotecnologias com embriões. Acta Scientiae Veterinariae, v. 35, p. 787-792, 2007. Suplemento 3.

BROWN, B. W.; RADZIEWIC, T. Production of sheep embryos in vitro and development of progeny following single and twin embryo transfers. Theriogenology, v. 49, n. 8, p. 1525 1536, 1998.

COGNIÉ, Y.; BARIL, G. Le point sur la production et le transfert d'embryons obtenus in vivo et invitro chez la brebis et la chèvre. INRA Productions Animales, v. 15, p. 199-207, 2002.

KILLEN, I. D.; CAFFERY, G. J. Uterine insemination of ewes with the aid of a laparoscope. Australian Veterinary Journal, v. 59, n. 3, p. 95, 1982.

COGNIÉ, Y.; POULIN, N.; LOCATELLI, Y.; MERMILLOD, P. State-of-the-art production, conservation and transfer of in-vitro-produced embryos in small ruminants. Reproduction, Fertility and Development, v. 16, p. 437-445, 2004.

COX, J. F.; ALFARO, V. In vitro fertilization and development of OPU derived goat and sheep oocytes. Reproduction Domestic Animals, v. 42, n. 1, p. 83-87, 2007.

CURET, M. J.; VOGT, D. A.; SHOB, O.; QUALLS, C.; IZQUIERDO, L. A.; ZUCKER, K. Effects of $\mathrm{CO}_{2}$ pneumoperitoneum in pregnant ewes. Journal of Surgical Research, v. 63, n. 1, p. 339-344, 1996.

CUSHWA, W. T.; BRADFORD, G. E.; STABENFELDT, G. H.; BERGER, Y. M.; DALLY, M. R. Ram influence on ovarian and sexual activity in anestrous ewes: effects of isolation of ewes from rams before joining and date of ram introduction. Journal Animal Science, v. 70, n. 4, p. 1195-1200, 1992. 
D'ALESSANDRO, A. G.; MARTEMUCCI, G.; TAIBI, L. How the FSH/LH ratio and dose numbers in the p-FSH administration treatment regimen, and insemination schedule affect superovulatory response in ewes. Theriogenology, v. 63, n. 6, p. 1764-1774, 2005.

DATTENA, M.; PTAK, G.; LOI, P.; CAPPAI, P. Surviv land viability of vitrified in vitro and in vivo produced ovine blastocysts. Theriogenology, v. 53, n. 8, p. 1511-1519, 2000.

EHLING, C.; WIRTH, P.; SCHINDLER, L.; HADELER, K. G.; DÖPKE, H. H.; LEMME, E.; HERRMANN, D.; NIEMANN, H. Laparoscopical intrauterine insemination with different doses of fresh, conserved, and frozen semen for the production of ovine zygotes.

Theriogenology, v. 60, n. 4, p. 777-787, 2003.

GARDNER, D. K.; LANE, M.; SPITZER, A.; BATT, P. A. Enhanced rates of cleavage and development for sheep zygotes cultured to the blastocyst stage in vitro in the absence of secrum and somatic cells: amino acids, vitamins, and culturing embryos in groups stimulate development. Biology of Reproduction, v. 50, n. 2, p. 390-400, 1994.

GRAZUL-BILSKA, A. T.; CHOI, J. T.; BILSKI, J. J.; WEIGL, R. M.; KIRSCH, J. D.; KRAFT, K. C.; REYNOLDS, L. P.; REDMER, D. A. Effects of epidermal growth factor on early embryonic development after in vitro fertilization of oocytes collected from ewes treated with follicle stimulating hormone. Theriogenology, v. 59, n. 5-6, p. 1449-1457, 2003.

GREEN, R. E.; SANTOS, B. F. S.; SICHERLE, C. C.; LANDIM-ALVARENGA, F. C.; BICUDO, S. D. Taxas de prenhez após inovulação de embriões ovinos vitrificados ou congelados. Acta Scientiae Veterinariae, v. 35, p. 979, 2007b. Suplemento 3.

GREEN, R. E.; SANTOS, B. F. S.; SICHERLE, C. C.; TACONELI, C.; BICUDO, S. D. Efeitos da administração de D-Clopostenol na taxa de ovulação, recuperação e viabilidade embrionária em ovelhas superovuladas. Acta Scientiae Veterinariae, , v. 35, p. 1223, 2007a. Suplemento 3.

HILL, J. R.; THOMPSON, J. A. Factors affecting pregnancy rates following laparoscopic insemination of 28,447 merino ewes under commercial conditions: a survey. Theriogenology, v. 49, n. 4, p. 697-709, 1998.

HOLM, P.; WALKER, S. K.; SEAMARK, R. F. Embryo viability, duration of gestation and birth weight I sheep after transfer of in vitro matured and in vitro fertilized zygotes cultured in vitro or in vivo. Journal of Reproduction and Fertility, v. 107, n. 2, p. 175-181, 1996.

JOHNSON, G. F.; TWEDT, D. C. Endoscopy and laparoscopy in the diagnosis and management of neoplasia in small animals. Veterinary Clinics North America, v. 7, n. 1, p. 77-92, 1977. 
JONES, B. D. Laparoscopy. Veterinary Clinics North America, v. 20, n. 5, p. 1243-1263, 1990.

KÜHHOLZER, B.; MÜLLER, S.; TREUER, A.; SEREGI, J.; BESENFELDER, U.; BREM, G. Repeated endoscopic ovum pick-up in hormonally untreated ewes: a new technique.

Theriogenology, v. 48, n. 4, p. 545-550, 1997.

LYMBEROPOULOS, A. G.; AMIRIDIS, G. S.; KÜHHOLZER, B.; BESENFELDER, U.; CHRISTODOULOU, V.; VAINAS, E.; BREM, G. Fertilization and embryo recovery rates in superovulated chios ewes after laparoscopic intrauterine insemination. Theriogenology, v. 55, n. 9 , p. 1855-1862, 2001.

MARTÍNEZ, A. G.; VALCÁRCEL, A.; FURNUS, C. C.; MATOS, D. G.; IORIO, G.; HERAS, M. A. Cryopreservation of in vitro-produced ovine embryos. Small Ruminant Research, v. 63, n. 3, p. 288-296, 2006.

MCEVOY, T. G.; ROBINSON, J. J.; AITKEN, R. P.; ROBERTSON, I. S. The effect of time on intrauterine insemination on the development and viability of embryos collected from superovulated ewes. Theriogenology, v. 46, n. 4, p. 727-738, 1996.

MEGALE, F.; FINCHER, M.G.; MCENTEE, K. Peritoneoscopy in the cow: visualization of the ovaries, oviducts and uterine horns. Cornell Veterinarian, v. 46, p. 109-121, 1956.

MOSES, D.; MARTÍNEZ, A. G.; IORIO, G.; VALCÁRCEL, A.; HAM, A.; PESSI, H.; CASTAÑÓN, R.; MACIÁ, A.; HERAS, M. A. A large-scale program in laparoscopic intrauterine insemination with frozen-thawed semen in Australian merino sheep in Argentine Patagonia. Theriogenology, v. 48, n. 4, p. 651-657, 1997.

NAQVI, S. M. K.; MAURYA, V. P.; GULYANI, R.; JOSHI, A.; MITTAL, J. P. The effect of thermal stress on superovulatory response and embryo production in Bharat Merino ewes.

Small Ruminant Research, v. 55, n. 1-3, p. 57-63, 2004.

PAPADOPOULOS, S.; RIZOS, D.; DUFFY, P.; WADE, M.; QUINN, K.; BOLAND, M. P.; LONERGAN, P. Embryo survival and recipient pregnancy rates after transfer of fresh or vitrified, in vivo or in vitro produced ovine blastocysts. Animal Reproduction Science, v. 74, n. 1-2, p. 35-44, 2002.

PHILLIPPO, M.; SWAPP, G. H.; ROBINSON, T. J.; GILL, J. C. The diagnosis of pregnancy and estimation of foetal numbers in sheep by laparoscopy. Journal of Reproduction and Fertility, v. 27, n. 1, p. 129-132, 1971. 
PHILLIPPO, M; RHIND, S.M. A new laparoscopic thechnique for the diagnosis of pregnancy and estimation of foetal loss in sheep. Journal of Agricultural Science, v. 89, n. 1, p. 251$252,1977$.

PTAK, G.; DATTENA, M.; LOI, P.; TISCHNER, M.; CAPPAI, P. Ovum pick-up in sheep: efficiency of in vitro embryo production, vitrification and birth of offspring. Theriogenology, v. 52, n. 6, p. 1105-1114, 1999.

RODRÍGUES, C.; ANEL, L.; ALVAREZ, M.; ANEL, E.; BOIXO, J. C.; CHAMORRO, C. A.; PAZ, P. Ovum pick-up in sheep: a comparison between different aspiration devices for optimal oocyte retrieval. Reproduction in Domestic Animals, v. 41, n. 2, p. 106-113, 2006.

SALLES, H. O. Inseminação artificial por via transcervical em ovinos. In: Empresa Brasileira de Pesquisa Agropecuária (EMBRAPA). Artigos técnicos. Sobral, [2004?]. Disponível em : $<$ http://www.cnpc.embrapa.br/artigo-2.htm $>$. Acesso em : 12 nov. 2007.

SCHIEWE, M. C.; BUSH, M.; STUART, L. S.; WILDT, D. E. Laparoscopic embryo transfer in domestic sheep a preliminary. Theriogenology, v. 22, n. 6, p. 675-682, 1984.

SCHNEIDER, F.; OTTO, F. Laparoscopic examination of the internal genital organs of cattle. Schweizer Archiv für Tierheilkunde, v. 116, n. 2, p. 103-109, 1974.

SILVA, L. C. L. C. Emprego da laparoscopia na colheita de biópsica hepática em eqüino: estudo da técnica e avaliação pós-operatória. 1998. 88 f. Tese (Doutorado) - Faculdade de Medicina Veterinária e Zootecnia, Universidade de São Paulo, São Paulo, 1998.

SILVA, N. Q.; MEGALE, F. Peritoneoscopy in the mare. Arquivos da Escola de Veterinária da Universidade Federal de Minas Gerais, v. 23, p. 91 -101, 1971.

SNYDER, D. A.; DUKELOW, R. Laparoscopic studies of ovulation, pregnancy diagnosis, and follicle aspiration in sheep. Theriogenology, v. 2, n. 6, p. 143-148, 1974.

STANGL, M.; KÜHHOLZER, B.; BESENFELDER, U.; BREM, G. Repeated endoscopic ovum pick-up in sheep. Theriogenology, v. 52, n. 4, p. 709-716, 1999.

TABET, A. F. Comparação entre duas técnicas de biópsia renal guiada por laparoscopia em eqüinos. 2003. 73 f. Dissertação (Mestrado) - Faculdade de Medicina Veterinária e Zootecnia, Universidade de São Paulo, São Paulo, 2003.

TERVIT, H. R. Laparoscopy/laparotomy oocyte recovery and juvenile breeding. Animal Reproduction Science, v. 42, n. 1-4, p. 227-238, 1996. 
THOMPSON, J. G.; GARDNER, D. K.; PUGH, P. A.; MCMILLAN, W. H.; TERVIT, H. R. Lamb birth weight is affected by culture system utilized during in vitro pre-elongation development of ovine embryos. Biology of Reproduction, v. 53, n. 6, p. 1385-1391, 1995.

TIBARI, A.; ANOUASSI, A.; KHATIR, H. Update on reproductive biotechnologies in small ruminants and camelids. Theriogenology, v. 64, p. 618-638, 2005.

WANI, N. A. In vitro maturation and in vitro fertilization of sheep oocytes. Small Ruminant Research, v. 44, n. 2, p. 89-95, 2002.

WILSON, G. L. Laparoscopic examination of mares. Veterinary Medicine, Small Animal Clinician - Equine Practice, v. 78, n. 10, p. 1629-1633, 1983.

WINDSOR, D. P.; SZÉLL, A. Z.; BUSCHBECK, C.; EDWARD, A. Y.; MILTON, J. T. B.; BUCKRELL, B. C. Transcervical artificial insemination of Australian merino ewes with frozen-thawed semen. Theriogenology, v. 42, n. 1, p. 147-157, 1994.

WISHART, D. F.; SNOWBALL, J. B. Endoscopy in cattle: observation of the ovary in situ. Veterinary Record, v. 92, n. 6, p. 139-143, 1973.

WULSTER-RADCLIFFE, M. C.; LEWIS, G. S. Development of a new transcervical artificial insemination method for sheep: effects of a new transcervical artificial insemination catheter and traversing the cervix on semen quality and fertility. Theriogenology, v. 58, n. 7, p. 1361$1371,2002$. 
. Representação dos índices totais obtidos das fases 1, 2, 3 e 4

\begin{tabular}{|c|c|c|c|c|c|c|c|c|c|c|c|c|c|c|c|c|}
\hline Fases & LOPU & $\begin{array}{l}\text { Fol. } \\
\text { Punc }\end{array}$ & $\begin{array}{l}\text { M.Fol/ } \\
\text { LOPU }\end{array}$ & Oó & $\begin{array}{l}\text { Oól } \\
\text { Fol }\end{array}$ & $\begin{array}{l}\text { M.Oó/ } \\
\text { LOPU }\end{array}$ & $\begin{array}{c}\text { Emb } \\
\text { D2 }\end{array}$ & $\begin{array}{l}\text { M.Emb/ } \\
\text { LOPU }\end{array}$ & $\begin{array}{l}\text { Emb/ } \\
\text { Oó }\end{array}$ & $\begin{array}{l}\mathrm{No} \\
\mathrm{Rec}\end{array}$ & $\begin{array}{l}\text { M.Emb/ } \\
\text { Rec }\end{array}$ & $P+$ & $\begin{array}{l}\mathrm{P}+1 \\
\mathrm{Rec}\end{array}$ & Fetos & $\begin{array}{l}\text { Fetos/ } \\
\text { TE }\end{array}$ & $\begin{array}{l}\text { M.Fetos/ } \\
\text { LOPU }\end{array}$ \\
\hline 1 & 12 & 124 & $\begin{array}{c}10,3^{\mathrm{a}} \\
(1,9)\end{array}$ & 88 & $\begin{array}{c}71 \%^{\mathrm{a}} \\
(88 / 124)\end{array}$ & $\begin{array}{l}7,3^{\mathrm{a}} \\
(0,1)\end{array}$ & & & & & & & & & & \\
\hline 2 & 8 & 62 & $\begin{array}{c}7,8^{a, b} \\
(1,0)\end{array}$ & 46 & $\begin{array}{l}74 \%^{\mathrm{a}} \\
(46 / 62)\end{array}$ & $\begin{array}{l}5,8^{\mathrm{a}} \\
(0,1)\end{array}$ & 22 & $\begin{array}{l}2,8^{\mathrm{a}} \\
(0,8)\end{array}$ & $\begin{array}{l}48 \%{ }^{a} \\
(22 / 46)\end{array}$ & 10 & 2,2 & 7 & $\begin{array}{c}70 \%^{a, b} \\
(7 / 10)\end{array}$ & 8 & $8 / 10^{a, b}$ & $\begin{array}{l}1,0^{b} \\
(0,3)\end{array}$ \\
\hline
\end{tabular}

\begin{tabular}{|c|c|c|c|c|c|c|c|c|c|c|c|c|c|c|c|c|}
\hline Fases & LOPU & $\begin{array}{l}\text { Fol. } \\
\text { Punc }\end{array}$ & $\begin{array}{l}\text { M.Fol/ } \\
\text { LOPU }\end{array}$ & Oó & $\begin{array}{l}\text { Oól } \\
\text { Fol }\end{array}$ & $\begin{array}{l}\text { M.Oó/ } \\
\text { LOPU }\end{array}$ & $\begin{array}{c}\text { Emb } \\
\mathrm{D} 2\end{array}$ & $\begin{array}{l}\text { M.Emb/ } \\
\text { LOPU }\end{array}$ & $\begin{array}{c}\text { Emb/ } \\
\text { Oó }\end{array}$ & $\begin{array}{c}\text { No } \\
\text { Rec }\end{array}$ & $\begin{array}{c}\text { M.Emb/ } \\
\text { Rec }\end{array}$ & $\mathrm{P}+$ & $\begin{array}{l}\mathrm{P}+1 \\
\mathrm{Rec}\end{array}$ & Fetos & $\begin{array}{c}\text { Fetos/ } \\
\text { TE }\end{array}$ & $\begin{array}{c}\text { M.Fetos/ } \\
\text { LOPU }\end{array}$ \\
\hline 3 & 8 & 54 & $\begin{array}{l}6,8^{b} \\
(1,0)\end{array}$ & 50 & $\begin{array}{l}93 \%{ }^{\mathrm{b}} \\
(50 / 54)\end{array}$ & $\begin{array}{l}6,3^{\mathrm{a}} \\
(0,1)\end{array}$ & 32 & $\begin{array}{c}4,0^{\mathrm{ab}} \\
(0,9)\end{array}$ & $\begin{array}{l}64 \%^{a, b} \\
(32 / 50)\end{array}$ & 14 & 2,3 & 6 & $\begin{array}{l}43 \%{ }^{a} \\
(6 / 14)\end{array}$ & 10 & $10 / 14^{b}$ & $\begin{array}{l}1,3^{b} \\
(0,7)\end{array}$ \\
\hline 4 & 9 & 80 & $\begin{array}{c}8,9^{a, b} \\
(1,1)\end{array}$ & 75 & $\begin{array}{l}94 \%{ }^{\mathrm{b}} \\
(75 / 80)\end{array}$ & $\begin{array}{l}8,3^{\mathrm{a}} \\
(0,1)\end{array}$ & 57 & $\begin{array}{l}6,3^{b} \\
(1,0)\end{array}$ & $\begin{array}{l}76 \%{ }^{b} \\
(57 / 75)\end{array}$ & 20 & 2,9 & 17 & $\begin{array}{l}85 \%{ }^{\mathrm{b}} \\
(17 / 20)\end{array}$ & 30 & $30 / 20^{a}$ & $\begin{array}{l}3,3^{\mathrm{a}} \\
(0,6)\end{array}$ \\
\hline
\end{tabular}

Valores com letras diferentes na mesma coluna diferem significativamente $(\mathrm{P}<0,05)$.

Legenda:

LOPU - laparoscopic ovum pick-up / punção dos folículos ovarianos

Fol Punc - folículos puncionados

M.Fol/LOPU - média de folículos puncionados por LOPU

Oó - oócitos

Oó/Fol - Taxa de recuperação (total de folículos puncionados / total de oócitos recuperados

M. Oó/LOPU - Média de oócitos recuperados por sessão de LOPU

Emb. D2 - total de embriões clivados produzidos (dia 2 pós fecundação)

M. Emb/LOPU - Média de embriões clivados produzidos por sessão de LOPU

Emb. / Oó - Taxa de conversão de oócitos para embriões clivados

No Rec - Número de receptoras utilizadas na fase

M.Emb/Rec - Número médio de embriões transferidos por receptora

$\mathrm{P}+$ - Número de receptoras prenhes na fase

$\mathrm{P}+/ \mathrm{Rec}$ - Taxa de prenhez - total de receptoras prenhes por total de receptoras transferidas

M.Fetos / LOPU - Média de fetos por sessão de LOPU 